\title{
A Strategic Perspective on Competition between Pipeline Gas and LNG
}

\author{
Robert A. Ritz
}

\begin{abstract}
Global gas markets feature two types of suppliers: piped gas and LNG exporters. Pipelines have a high degree of "asset specificity" : once built, they are physically bound to a particular route. LNG is transported by tanker, with a choice of export markets. Put simply: LNG is mobile, pipelines are not. This paper uses game-theoretic modelling to show how its commitment to serving a single market confers a strategic advantage on piped gas. By "overinvesting" in its own market, a pipeline exporter can induce LNG rivals to shift sales to their other markets. The model helps understand competition between Russian piped gas and Qatari LNG. It shows how Russia's dependence on Europe can be good news for gas buyers, why these nonetheless strongly benefit from diversifying into LNG imports, and how the Herfindahl index of imports can mismeasure "supply security". The paper also discusses Russia's evolving gas export strategy, including gas deals with China.
\end{abstract}

Keywords: Global gas markets, Strategic competition, Security of supply, Diversification strategy

https://doi.org/10.5547/01956574.40.5.rrit

\section{INTRODUCTION}

Natural gas is of significant commercial and public-policy interest. It provides close to $25 \%$ of worldwide primary energy consumption, being widely used in power generation, residential heating and as a feedstock for industrial production. Following the 2015 COP-21 Paris climate conference, many policy analysts also see an important medium-term role for gas in the transition to a low-carbon economy (e.g., IEA, 2017) — notably given that it has half the $\mathrm{CO}_{2}$-emissions intensity of coal.

Competition in the international natural gas industry features two types of suppliers: traditional sellers of gas that is transported by pipeline, such as Russia/Gazprom, and exporters of seaborne liquefied natural gas (LNG), notably Qatar. With the expansion of international trade over the last decade, pipeline gas and LNG now increasingly compete head-to-head, notably in Europe. Yet they are also fundamentally different. Gas pipelines are large infrastructure investments with a very high degree of "asset specificity" : once built, they are physically bound to a particular route, with no alternative use (Williamson, 1985; Makholm, 2012). They are also observable to market participants and largely irreversible, giving them substantial commitment value in business strategy (Ghemawat, 1991). LNG, by contrast, is super-cooled and then transported by tanker, which gives exporters a choice of markets for any given cargo. Put simply: LNG is mobile, pipelines are not.

a Cambridge Judge Business School and Energy Policy Research Group (EPRG), University of Cambridge, United Kingdom. Send correspondence to Energy Policy Research Group (EPRG), Cambridge Judge Business School, Trumpington Street, Cambridge CB2 1AG, United Kingdom. E-mail: r.ritz@jbs.cam.ac.uk 
The objective of this paper is to use the toolkit of game theory to understand the implications of this asymmetry for competition in global gas markets.

International gas trade is divided into three main regional markets-Europe, Asia and North America (Stern, 2012) — and is around $70 \%$ by pipeline and $30 \%$ as LNG. Most European imports come via pipelines from Russia while LNG has played an important role, e.g., for the UK and parts of Southern Europe. By contrast, several large Asian importers lack pipeline connections; LNG covers $100 \%$ of Japanese and South Korean imports, and Japan is the world's largest LNG importer. With the rise of hydraulic fracturing, the US has become the world's largest gas producer - but has until recently been disconnected from international trade due to a lack of LNG export infrastructure (Joskow, 2013). Qatar is the world's largest LNG exporter with a global market share of almost 35\%; it has supplied almost half of European LNG and been the largest player in Asia. ${ }^{1}$ Gazprom is the world's largest supplier of pipeline gas, holding a legal monopoly in Russia over exports of piped gas. The "balance of power" between Russia and Qatar has played a central role for competition over the last 10 years (Stern and Rogers, 2014).

Section 2 begins with further details on the pipeline and LNG "production technologies" for the export of natural gas (and their business models), gives an overview of international trade and market structure in the regionalized global gas market, and discusses the importance of geopolitics for natural gas. Section 3 presents a simple game-theoretic model that captures these essential features of competition in global gas. The model has two markets $A$ and $B$ and two strategic suppliers: an LNG exporter serves both markets $A$ and $B$ while a pipeline supplier sells only to market $B$. Each market also features a competitive fringe of smaller non-strategic suppliers. It is a two-stage game of capacity investments followed by quantity competition, in which the LNG exporter in the 2nd stage chooses how to split its sales across the two markets. The discussion focuses mostly on the rivalry between Russian piped gas (Gazprom) and Qatari LNG in Europe (market $B$ )—where Qatar also serves Asia (market $A){ }^{2}$

Section 4 solves for the equilibrium, and Section 5 then presents the main insights from the analysis. It begins by showing how its commitment to serving a single market confers a strategic advantage on a pipeline supplier: it recognizes that its LNG rival has an alternative use for its capacity in market $A$ - and can therefore be induced in the 2nd stage to cede market share of the common market $B$. As this raises its return on investment, the pipeline supplier aggressively "overinvests" in capacity. By contrast, the pipeline player itself has no such outside option because its investment is specific to market $B$. This strategic effect raises the market share and profits of pipeline gas - at the expense of LNG.

The analysis shows how Russia's dependence on Europe can benefit local gas buyers: its strategic overinvestment raises the intensity of competition, leading to higher production and a lower gas price. ${ }^{3}$ For the same reason, the widely-used Herfindahl index may give a misleading pic-

1. This paper follows the literature in treating countries as players; there is often a close association with a company, e.g., Russia (Gazprom), Norway (Equinor, formerly Statoil), Algeria (Sonatrach), Qatar (Qatargas). Other large multimarket LNG exporters that serve both Europe and Asia include Nigeria and Trinidad \& Tobago; future US LNG exports will be in a strategically similar position.

2. Russia also has a small presence in LNG, currently at less than $5 \%$ of its total gas sales. This LNG is based out of different gas fields than its pipeline sales to Europe, so in effect represents a different player to the main one considered in this paper. See Section 8 for further discussion.

3. Gazprom assumes a role similar to that of a classic Stackelberg leader (see, e.g., Tirole (1988, Section 8.2)) — even though the timing of the model has simultaneous choices of capacities and outputs; the model does not examine issues of entry deterrence and pre-emptive investment. 
ture of "security of supply" : in some cases, higher import concentration is good news for buyers. ${ }^{4}$ The model can also explain why gas-importing countries nonetheless like to diversify into LNGand how Lithuania's first LNG import terminal yielded a larger-than-expected price concession from Gazprom. Finally, it sheds light on how the strategic players optimally respond to additional entry into the European gas market (e.g., by smaller LNG exporters): at equilibrium, the pipeline player (Gazprom) more strongly "makes room" than a large LNG player (Qatar) to an expansion of the competitive fringe.

Section 6 uses an illustrative calibration to global gas market data to demonstrate that the strategic effects studied in the paper can be quantitatively significant. Section 7 argues that the main insights are robust to different model specifications, including the strategic players having "political objectives" that depart from narrow economic profit-maximization. Section 8 discusses Russia's evolving gas export strategy, with a focus on how a "pivot to Asia" — notably recent gas deals with China-may undermine Gazprom's position in Europe. Section 9 gives concluding remarks and suggestions for future research.

Contribution to the literature. This paper complements the existing literature on natural gas markets, which is dominated by large-scale numerical Cournot-style models (e.g., Egging, Gabriel, Holz and Zhuang, 2008; Holz, von Hirschhausen and Kemfert, 2008; Chyong and Hobbs, 2014; Growitsch, Hecking and Panke, 2014). ${ }^{5}$ It is well-established in this literature that the global gas market is not perfectly competitive; market power is an important driver of prices and trade flows. ${ }^{6}$ Such large-scale models are well-suited to policy analysis via numerical simulation of scenarios in terms of gas demand, investment volumes, etc. However, their complexity means that it can be difficult to understand what is driving the numbers. This paper instead emphasizes the microeconomic intuition and strategic interaction between key producers. Another important difference is that largescale gas models are typically solved as "open loop" equilibria, in which capacity and production decisions are, in effect, made simultaneously; the analysis here derives a "closed loop" equilibrium in which players' capacity choices have an impact on subsequent play. ${ }^{7}$ This distinction means that the strategic issues studied in this paper are absent from this prior literature.

This paper also relates to the industrial-organization literature on multimarket oligopoly, e.g., Bulow, Geneakoplos and Klemperer (1985); Cooper (1989); Shelegia (2012); Arie, Markovich and Sela (2017). The model here builds on the work of Shelegia (2012); key differences are that: (i) firms here are heterogeneous in terms of production and investment costs (piped gas vs LNG), and (ii) demand conditions vary across markets (Asia vs Europe). Both of these features are central to the global-gas application presented here.

4. There are many different definitions of "security of supply" . A representative one is "the availability of sufficient supplies at affordable prices" (Yergin, 2006). While this definition is also imprecise, it has similarities with the standard definition of consumer surplus: all else equal, a lower price and higher consumption are good for security of supply and raise consumer surplus. Of course, the present model should not be taken to capture all the issues that are relevant in practice; the more modest objective here is to point out there exists a strategic consideration which goes against the "conventional wisdom" on supply security.

5. Smeers (2008) gives a valuable perspective on this literature, including earlier work from the 1990s.

6. Ritz (2014) shows that LNG exporter market power can explain observed global gas prices and trade patterns, combined with limited access to the LNG tanker market (which makes it difficult for third-party traders to arbitrage prices between different regions). Li, Joyeux and Ripple (2014) also find that the world gas market is not fully integrated.

7. In the business strategy literature, Hawk, Pacheco-de-Almeida and Yeung (2013) empirically examine entry strategies into the then-emerging LNG market over the period from 1996 to 2007 and also emphasize the commitment role of capacity investments in business practice. 
A number of considerations are beyond the scope of the present analysis. Similar to most large-scale gas models, it does not incorporate the details of long-term contracts between buyers and sellers (see e.g., Brito and Hartley (2007), Hartley (2015), Neumann, Rüster and von Hirschhausen (2015)), does not study the related topic of opportunistic behaviour in form of "hold up" by trading partners, and does not feature intertemporal constraints on resource extraction à la Hotelling or other issues such as demand seasonality and gas storage. The paper also does not address issues arising from the 2014-16 crash in commodity markets.

\section{COMPETITION AND TRADE IN GLOBAL GAS MARKETS}

This section presents a selective overview of global gas markets focusing on what is most relevant for the themes developed in this paper. The overview is split into three parts: (1) the coexistence of two different "production technologies" - pipeline gas and LNG - and their business models; (2) the regional fragmentation of global gas together with significant market concentration in international trade, led by Russia (pipeline gas) and Qatar (LNG) as the largest exporters; and (3) the importance in the natural gas industry of geopolitics and concerns about supply security.

Production technologies: Pipeline gas vs LNG. There are two technologies for the transport of natural gas: international trade is around $70 \%$ by pipeline and $30 \%$ as LNG, with LNG expected to continue to grow more strongly than pipeline trade (IEA, 2017).

The value chain for pipeline exports has three main stages. First, the upstream extraction and production of natural gas. Second, at the midstream level, pipeline transport from the exporter to the importing country, which usually (but not always) is onshore. Finally, downstream, the distribution via the local gas network and consumption by end users. The upstream and midstream parts of this value chain require large capital investments, varying with the size and location of an export project. Additional maintenance investment is required over time to ensure safety and maintain output as the gas field and pipelines age (Smil, 2015). In most cases today, the downstream gas network infrastructure in the importing country will already be in place.

The value chain for LNG differs in two main respects at the midstream stage. First, it instead involves the liquefaction of natural gas at very low temperature to raise its energy density for export on dedicated LNG tankers. Second, it then also involves regasification at the receiving LNG import terminal. Liquefaction and regasification mean that LNG is typically more expensive than an otherwise identical pipeline project. Yet LNG's comparative advantage is that it is often cheaper to transport over long distances than piped gas (Jensen, 2004). LNG has also become even more flexible in recent years with the rise of floating regasification (FSRU).

The traditional business model for pipeline projects is backward integration between the upstream and midstream stages; for example, Gazprom is vertically integrated into the extraction, production, pipeline transport and sale of natural gas. Similarly, for LNG, the traditional business model involves significant vertical integration; for example, Qatar is vertically integrated into the extraction of natural gas, liquefaction and owns a fleet of LNG tankers. ${ }^{8}$ Midstream regasification and downstream gas transmission have traditionally also been vertically integrated within a different entity; for example, in South Korea this has been Kogas as the national monopoly LNG buyer. ${ }^{9}$

8. Yergin (2011, Chapter 15) provides a useful perspective of the rise of Qatar as the top LNG exporter.

9. New LNG business models have been emerging. The US LNG export projects (e.g., Cheniere Energy) operate a tolling model without integration into extraction, production, shipping or regasification; instead, the owners of natural gas pay a service fee for access to the liquefaction unit. Other companies are specialized in LNG shipping (e.g., GasLog) or act as "aggregators" (e.g., BG Group, now part of Royal Dutch Shell) that engage in LNG price arbitrage over space and time. 
The details of ownership structure within the global gas industry are complex. ${ }^{10}$ First, some major LNG exporters are also partially forward-integrated with ownership stakes in downstream regasification facilities; for example, Qatar owns part of the South Hook LNG import terminal in the UK. ${ }^{11}$ Second, some major LNG importers have ownership stakes further upstream; one example is Kogas's minority stakes in Australian LNG liquefaction projects. Third, large projects are often joint ventures (JVs) with international energy companies; for example, Qatar's LNG interests are run by state-controlled Qatar Petroleum's Qatargas and Rasgas subsidiaries which, in turn, involve JVs with different international partners. ${ }^{12}$ Finally, Gazprom is a publicly-listed company with many shareholders-but remains majority-controlled by the Russian state.

Regional markets, international trade and market structure. Global gas trade is divided into three main regional markets-Asia, Europe, and North America (Stern, 2012). Significant regional price differentials have existed for many years, and can partly be explained by the large gas exporters exercising market power (Ritz, 2014). The "balance of power" between Russia and Qatari LNG in the European market has played a central role for competition in global gas over the last 10 years (Stern and Rogers, 2014). With the rise of hydraulic fracturing, the US has again become the world's largest gas producer. Yet it has until recently been disconnected from international trade (apart from pipeline trade with Canada) given its lack of LNG export infrastructure (Joskow, 2013). ${ }^{13}$

Gas prices have usually been highest in the Asian market, followed by Europe and then North America. In the period from 1999 to 2017, the average "Asian premium" over European gas prices was $36 \% .{ }^{14}$ Asian prices were lower for a short period during the 2008-9 financial crisis but then rose well above European prices again following the Fukushima accident of March 2011. The 2013 average gas price was close to US\$17 per million metric British thermal units in Asia (Japan and South Korea), US\$11/mmbtu in Europe (UK and Germany), and US\$4 in the US (at Henry Hub). As of 2018, these regional price differentials remain-even if they are not quite as pronounced.

There is significant market concentration in global gas markets, with Russia (pipeline gas) and Qatar (LNG) as the two major players together accounting for around 35\% of international trade (outside North America). ${ }^{15}$ Russia is the world's 2nd largest producer of gas and its largest gas exporter, with Gazprom controlling around $75 \%$ of production and holding a legal monopoly over exports of piped gas. ${ }^{16}$ Of its pipeline exports, over $80 \%$ go to European markets while the remainder goes to countries of the former Soviet Union. Russia's share of international pipeline trade (outside North America) is around 35\%; other large pipeline producers are Norway, the Netherlands and Algeria - which all also serve the European market. On the LNG side, Qatar has been the world's largest exporter with a global market share of almost 35\%. Its main destinations are both "mid-price" Europe (especially UK and Italy) and "high-price" Asia (especially Japan and South

10. See GIIGNL (2017) for a useful overview of the ownership of the global LNG infrastructure.

11. Ownership of regasification terminals can be diverse. Of the UK's three main regasification terminals, South Hook is owned by Qatar, ExxonMobil and Total; Dragon LNG is owned by Petronas and Royal Dutch Shell; and Grain is owned by National Grid (the national transmission system operator).

12. To illustrate, the JV partners in the Qatargas projects are: ExxonMobil, Total, Mitsui and Marubeni (Qatargas I); ExxonMobil (II); ConocoPhilips and Mitsui (III); and Royal Dutch Shell (IV).

13. Since 2016, Cheniere Energy's Sabine Pass facility has delivered LNG cargos to both Asia and Europe, and the US over the next five years now looks set to become a major LNG-exporting country.

14. Calculation based on IMF Primary Commodity Price data, available at https://www.imf.org/external $/ \mathrm{hp} / \mathrm{res} / \mathrm{com}$ $\bmod /$ index.aspx

15. The data in this discussion is based on BP (2015).

16. See Section 8 for discussion of Russia's LNG sales. 
Korea), with a split of around $25 \%$ and $75 \%$. The next largest LNG exporters are Nigeria, Australia, Indonesia, Malaysia, and Trinidad \& Tobago. In addition to Qatar, other multimarket LNG exporters serving both Europe and Asia include Nigeria, Trinidad \& Tobago, and Peru.

From the European viewpoint, around $80 \%$ of total gas imports are by pipeline and $20 \%$ as LNG. Around $40 \%$ of Europe's total gas consumption is met via Russian pipelines, and the majority of imports come from Russia. Central and Eastern Europe are more reliant on Russia while LNG plays a particularly important role for the UK, Italy, and Spain (for which LNG imports can exceed pipeline trade) - and close to $50 \%$ of European LNG imports come from Qatar.

Asian gas markets rely more heavily on LNG imports. LNG makes up $100 \%$ of gas imports for Japan, South Korea, Taiwan and India. Japan is the world's largest LNG importer, with Qatar as its top supplier. China imports both LNG and pipeline gas (almost entirely from Turkmenistan) as does Thailand (with pipeline imports from its Joint Development Area with Myanmar). Overall, the split of Asian gas imports is the opposite of Europe: around 80\% LNG and 20\% pipeline.

Geopolitics. The history of international trade in natural gas is intertwined with geopolitics and concerns over "security of supply". There is often a close association between a gas-exporting country and an individual company-e.g., Russia (Gazprom), Norway (Equinor, formerly Statoil), Algeria (Sonatrach), Qatar (Qatar Petroleum) — which is often state-controlled. For some exporting countries, especially in the Middle East, the value of energy-related exports has wider fiscal, political and macroeconomic relevance.

The importance of geopolitics has been particularly evident in the European gas market. Russia's pipeline exports to Europe began in the 1970s during the Cold War, partly as a result of the "Ostpolitik" pursued by Germany's Chancellor Willy Brandt. ${ }^{17}$ More recently, there have been several disputes between Russia and the Ukraine which serves as a transit country for natural gas flowing to Europe. In January 2009, this led to the interruption of gas supplies to several European countries-which heightened awareness of supply risks arising from Russia (Yergin, 2011). ${ }^{18}$ In 2011, the European Commission launched an antitrust case against Gazprom, primarily over accusations of anti-competitive practices towards smaller gas-importing countries in Eastern Europe. ${ }^{19}$

LNG is often seen as an opportunity to diversify gas imports beyond such "political" pipelines. This is particularly evident in the case of Lithuania which in 2014 opened its FSRU LNG import terminal, for the first time creating direct competition to piped gas from Russia. It has been suggested that the emergence of the US as a major LNG exporter may make the global gas market more transparent and "less political". Within the US, in turn, shale production has led to a change in rhetoric from a long-standing desire for "energy independence" to one of "energy abundance". Yet LNG is also not immune to political risk and supply disruptions, for example, in form of a blockage of tankers going through the Strait of Hormuz (Growitsch, Hecking \& Panke 2014). ${ }^{20}$

17. The US was initially politically opposed to Soviet gas exports to Europe; see "Reagan Lifts Sanctions on Sales for Soviet Pipeline; Reports Accord with Allies" (New York Times, 14 November 1982).

18. Several large-scale gas models have been used to quantify market impacts of supply disruptions to transit through Ukraine (e.g., Egging, Gabriel, Holz and Zhuang, 2008; Chyong and Hobbs, 2014).

19. The case concluded in May 2018 with a commitment by Gazprom to adjust its pricing practices; see "Brussels set for a compromise deal in Gazprom antitrust case" (Financial Times, 16 May 2018).

20. Political considerations and LNG industry structure may be interrelated in other ways. For example, the fact that Qatar, as its largest LNG supplier, owns part of the South Hook LNG import terminal is sometimes said to be beneficial for UK gas supply security - but it is perhaps not straightforward to disentangle to what extent this ownership stake is driven by economic and/or political motives. 
The next section presents a simple benchmark model that captures essential features of the global gas market, notably the co-existence of pipeline and LNG suppliers. The analysis derives implications for competition and supply security, and presents an illustrative calibration to market data on international trade flows and prices. Following this, Section 7 discusses robustness-including to issues of vertical integration and geopolitics.

\section{THE MODEL}

Setup. The model features two strategic suppliers and two markets, each with a competitive fringe. An LNG supplier, denoted as player 1, sells to both markets $A$ and $B$, with outputs denoted by $x_{1}, y_{1}$. A pipeline exporter, player 2 , supplies solely to market $B$, with sales of $y_{2}$. Market $A$ has a linear inverse demand curve $p^{A}\left(x_{1} ; x_{f}\right)=a-b\left(x_{1}+x_{f}\right)$, with parameters $a, b>0$, where $x_{f} \geq 0$ is (exogenous) supply by a competitive fringe. Similarly, market $B$ has linear demand $p_{j}^{B}\left(y_{1}, y_{2} ; y_{f}\right)=\alpha_{j}-\beta\left(y_{1}+y_{2}+y_{f}\right)$, where $\alpha_{j}, \beta>0$ (for $\left.j=1,2\right)$ and $y_{f} \geq 0$ is fringe supply.

The game has two stages. In the first stage, the strategic players simultaneously invest in production capacities, $K_{1}$ and $K_{2}$, respectively at unit costs of capacity $r_{1}>0$ and $r_{2}>0$. Both strategic players are thought of as vertically integrated: the pipeline player 2 has production of natural gas followed by pipeline transport; the LNG player 1 also has a liquefaction terminal and then transports by LNG tanker. The capacities $K_{j}(j=1,2)$ are thus best thought of as a "composite" measure of the scale of an optimally-designed LNG or pipeline project. ${ }^{21}$ In the second stage, they simultaneously decide how much output to sell into markets $A$ and $B$, at unit costs of production $c_{1}^{A}, c_{1}^{B} \geq 0$ (including transportation costs) for player 1 and $c_{2}^{B} \geq 0$ for player 2, subject to their installed capacities. ${ }^{22}$ There is no asymmetric information, choices are observable to players and for simplicity there is no discounting. Players maximize their respective profits and the equilibrium concept is subgame-perfect Nash equilibrium. ${ }^{23}$

Necessary conditions for an interior solution are (i) $p^{A}(0 ; 0)=a>r_{1}+c_{1}^{A}$ in market $A$ and $p_{j}^{B}(0,0 ; 0)=\alpha_{j}>r_{j}+c_{j}^{B}(j=1,2)$ in market $B$ (i.e., buyers' willingness-to-pay is sufficiently high for the markets to be economically viable), and (ii) $\phi_{j}>\frac{1}{2} \phi_{i}$, where $\phi_{j} \equiv\left(\alpha_{j}-r_{j}-c_{j}^{B}\right)>0$ is an index of the profitability of player $j=1,2, i \neq j$, in the common market $B$ (i.e., the two strategic players are not too asymmetric).

Assume that, in equilibrium, (i) both players sell positive amounts to their respective markets, and (ii) each player's total sales are at its capacity constraint. The precise parameter conditions

21. To give this a microfoundation, consider pipeline player 2's investment decision and suppose that its composite capital $K_{2}$ is made up of two types of capital input. The "upstream" $(U)$ investment $k_{2}^{U}$ has unit cost $r_{2}^{U}$ while the "midstream" $(M)$ investment $k_{2}^{M}$ has unit $\operatorname{cost} r_{2}^{M}$. Suppose further that these generate composite capital according to a Leontief production function $K_{2}=\min \left\{\theta^{U} k_{2}^{U}, \theta^{M} k_{2}^{M}\right\}$, where $\left(\theta^{U}, \theta^{M}\right)$ are productivity parameters. This function reflects the economic intuition that the different types of capital input need to be well-coordinated; too much, say, of the downstream asset is wasteful without a correspondingly-sized upstream asset. (Put simply, it makes no sense to build a giant export pipeline for a tiny gas field.) The player thus optimally invests such that $k_{2}^{U}=\left(\theta^{M} / \theta^{U}\right) k_{2}^{M}$. In accounting terms, the total investment cost is $r_{2}^{U} k_{2}^{U}+r_{2}^{M} k_{2}^{M}$; at the optimal design, this becomes $\left[r_{2}^{U} / \theta^{U}+r_{2}^{M} / \theta^{M}\right] K_{2}$. So the unit cost of composite capital $K_{2}$ is equal to a productivity-weighted average of the individual capital inputs, $r_{2} \equiv\left[r_{2}^{U} / \theta^{U}+r_{2}^{M} / \theta^{M}\right]$, just as in the main text.

22. That is, the short-run marginal cost of player 1 selling to market $A$ is $c_{1}^{A} \geq 0$ as long as $x_{1}+y_{1} \leq K_{1}$ and becomes $+\infty$ if $x_{1}+y_{1}>K_{1}$.

23. More generally, the first stage can represent any decisions that are taken before the actual production and delivery of the gas. This includes maintenance expenditure as well as financing and labour costs. The key consideration is that, for pipeline gas, these costs are specific to particular route while, for LNG, they are "global" and apply to subsequent delivery to multiple destinations. 
to ensure this are given in Lemma 2 below; roughly put, they require that fringe supplies $x_{f}, y_{f}$ are sufficiently small so as to not crowd the strategic players entirely out of the market.

Discussion. This model is a simplified representation of the global gas market. The two players can be thought of as Qatar (LNG) and Russia/Gazprom (piped gas) as the main strategic producers. Market $A$ is Asia — notably Japan and South Korea-principally served by LNG, while market $B$ is Europe, served both by LNG and pipeline. The competitive fringes $x_{f}, y_{f}$ can be interpreted as other small exporters (pipeline or LNG) serving the market. While not crucial for the main insights that follow, they deliver additional insight on how the strategic players respond to changes in competition.

The model allows for demand conditions and prices to vary across regional markets. It also allows piped gas and LNG to be imperfect substitutes in the eyes of consumers (via $\alpha_{1} \neq \alpha_{2}$ ) - and hence to have different sales prices in market $B$. This could reflect small differences in quality (e.g. due to chemical composition) or that buyers might have a slightly higher willingness-to-pay for "insurance" LNG supplies.

A key feature is that the model allows the pipeline gas and LNG to have different cost structures. In terms of investment costs (i.e., $r_{1}, r_{2}$ ), piped gas incurs capital costs for the pipeline construction while LNG involves investment costs for liquefaction and shipping. As the pipelines and LNG come from different physical locations, there may also be cost differences in the upstream gas fields. In terms of production costs (i.e., $c_{1}^{A}, c_{1}^{B}, c_{2}^{B}$ ), differences arise because transport costs vary depending on whether gas is moved by pipeline or an LNG tanker. Again, different physical locations also typically mean different production costs.

The assumption of binding capacity constraints, seems a reasonable simplification for this industry (in which any operational capacity is often fully used). Global LNG export capacity utilization rates have consistently been $80-90 \%$, with Qatar's liquefaction utilization reported as $100 \%$ (IGU, 2013). ${ }^{24}$ It is admittedly less accurate for Russian pipeline exports to Europe, for which average yearly utilization has recently varied between 64\% (2014) to 87\% (2017) (Henderson \& Sharples 2018). Yet this assumption greatly simplifies the analysis by reducing its dimensionality from five choice variables - two capacity choices $\left(K_{1}, K_{2}\right)$ plus three output choices $\left(x_{1}, y_{1}, y_{2}\right)$ - to three.

\section{SOLVING THE MODEL}

Define the players' revenues across the two markets, $R_{1}^{A}\left(x_{1} ; x_{f}\right)=p^{A} x_{1}$ and $R_{j}^{B}\left(y_{1}, y_{2} ; y_{f}\right)=p_{j}^{B} y_{j}(j=1,2)$ as well as the corresponding marginal revenues $M R_{1}^{A}\left(x_{1} ; x_{f}\right)=p^{A}-b x_{1}$ and $M R_{1}^{B}\left(y_{1}, y_{2} ; y_{f}\right)=p_{j}^{B}-\beta y_{j}(j=1,2)$.

Stage 2: Output decisions. Consider players' output choices in Stage 2, given Stage-1 investments. By assumption, producers are capacity-constrained, so LNG player 1's sales satisfy $x_{1}+y_{1}=K_{1}$ while $y_{2}=K_{2}$ for pipeline player 2 .

The remaining question is how player 1 splits its sales across markets: it maximizes profits by equalizing its marginal revenues, net of short-run marginal costs, across markets with $M R_{1}^{A}\left(x_{1} ; x_{f}\right)-c_{1}^{A}=M R_{1}^{B}\left(y_{1}, y_{2} ; y_{f}\right)-c_{1}^{B}$. Since both players are capacity-constrained, this can be rewritten as:

$$
M R_{1}^{A}\left(K_{1}-y_{1} ; x_{f}\right)-c_{1}^{A}=M R_{1}^{B}\left(y_{1}, K_{2} ; y_{f}\right)-c_{1}^{B} .
$$

24. By constrast, the global LNG import capacity utilization rate has been low and stable at around $40 \%$ since 2000 ; there are almost no countries in which these constraints are close to binding, and even Japan's utilization has only been around $50 \%$ (IGU, 2013) 
LNG player 1's choice of output to market $B$ thus depends on the capacity installed by its rival player 2; this plays a crucial role in what follows. In sum, given capacities $\mathbf{K}=\left(K_{1}, K_{2}\right)$, the strategic players' outputs are $x_{1}(\mathbf{K}), y_{1}(\mathbf{K}), y_{2}(\mathbf{K})=K_{2}$.

Stage 1: Capacity decisions. Anticipating these output decisions, consider players' capacity decisions at Stage 1. LNG player 1 chooses its investment to maximize its joint profits from both markets:

$$
\max _{K_{1}}\left\{R_{1}^{A}\left(x_{1}(\mathbf{K}) ; x_{f}\right)+R_{1}^{B}\left(y_{1}(\mathbf{K}), y_{2}(\mathbf{K}) ; y_{f}\right)-r_{1} K_{1}-\left[c_{1}^{A} x_{1}(\mathbf{K})+c_{1}^{B} y_{1}(\mathbf{K})\right]\right\},
$$

which makes explicit the indirect dependency of its revenues and production costs on both players' capacity choices. The first-order condition is:

$$
0=M R_{1}^{A} \frac{\partial x_{1}}{\partial K_{1}}+M R_{1}^{B} \frac{\partial y_{1}}{\partial K_{1}}-r_{1}-\left(c_{1}^{A} \frac{\partial x_{1}}{\partial K_{1}}+c_{1}^{B} \frac{\partial y_{1}}{\partial K_{1}}\right)
$$

Since $\partial x_{1} / \partial K_{1}+\partial y_{1} / \partial K_{1}=1$ (given the binding capacity constraint, total sales rise one-for-one with capacity) and using (1), the LNG player's capacity investment is such that:

$$
\left(M R_{1}^{A}-c_{1}^{A}\right)=\left(M R_{1}^{B}-c_{1}^{B}\right)=r_{1}>0 .
$$

This equates marginal revenue with long-run marginal cost (i.e., production cost plus capacity cost) for each market, $M R_{1}^{\ell}=r_{1}+c_{1}^{\ell}$ for $\ell=A, B$.

Hence the outcome in market $A$ is the residual monopolist's price, given its marginal cost $r_{1}+c_{1}^{A}$ and fringe supply $x_{f}$. Denoting the associated output by $x_{m} \equiv \frac{1}{2}\left(a-r_{1}-c_{1}^{A}-b x_{f}\right) / b$, it follows that $x_{1}=x_{m}$ and $y_{1}=K_{1}-x_{m}$.

The pipeline supplier 2 chooses its capacity investment to:

$$
\max _{K_{2}}\left\{R_{2}^{B}\left(y_{1}(\mathbf{K}), y_{2}(\mathbf{K}) ; y_{f}\right)-r_{2} K_{2}-c_{2}^{B} y_{2}(\mathbf{K})\right\}
$$

The first-order condition is:

$$
0=M R_{2}^{B} \frac{\partial y_{2}}{\partial K_{2}}+\frac{\partial R_{2}^{B}}{\partial y_{1}} \frac{\partial y_{1}}{\partial K_{2}}-r_{2}-c_{2}^{B} \frac{\partial y_{2}}{\partial K_{2}} .
$$

Given linear demand in market $B, \partial R_{2}^{B} / \partial y_{1}=-\beta y_{2}$, and similar to before, $\partial y_{2} / \partial K_{2}=1$, and so (4) can also be written as:

$$
M R_{2}^{B}+\beta\left(-\frac{\partial y_{1}}{\partial K_{2}}\right) y_{2}=r_{2}+c_{2}^{B}
$$

The "strategic effect" linking markets on the supply side. The pipeline supplier 2 recognizes that its capacity choice affects the product-market behaviour of LNG player 1 in their $\mathrm{co} \mathrm{m} \mathrm{mon}$ market $B$, via the "strategic effect" $\sigma \equiv\left(-d y_{1} / d K_{2}\right)$.

Lemma 1. The strategic effect that links markets $A$ and $B$ satisfies:

$$
\sigma \equiv\left(-\frac{\partial y_{1}}{\partial K_{2}}\right)=\frac{1}{2}\left(\frac{\beta}{b+\beta}\right) \in\left(0, \frac{1}{2}\right) \text {. }
$$


This expression can be understood as follows. A small increase $d K_{2}>0$ lowers player 1's marginal revenue in market $B$ by $d M R_{1}^{B}=\left(\partial M R_{1}^{B} / \partial y_{2}\right)\left(d K_{2}\right)=-\beta\left(d K_{2}\right)<0$. (This reflects that competition in market $B$ is in strategic substitutes (Bulow, Geneakoplos \& Klemperer 1985).) By how much does player 1 have to adjust its sales $y_{1}$ to market $B$ to adjust to restore optimality as per (1)? Cutting $y_{1}$ both raises $M R_{1}^{B}$ and lowers $M R_{1}^{A}$; specifically, $d M R_{1}^{B}=-2 \beta\left(d y_{1}\right)>0$ and $d M R_{1}^{A}=2 b\left(d y_{1}\right)<0$. This leads to the expression for $\sigma$ in Lemma 1.

The strategic effect $\sigma$ is thus driven solely by slopes of $M R_{1}^{A}$ and $M R_{1}^{B}$, not by the levels of marginal revenues in the two markets. As a result, it does not depend on the size of the competitive fringe in either market $\left(x_{f}, y_{f}\right)$ or on whether players' products are differentiated in market $B$ (i.e., $\left.\alpha_{1} \neq \alpha_{2}\right)$ or on the details of the players' cost structures $\left(r_{1}, r_{2}, c_{1}^{A}, c_{1}^{B}, c_{2}^{B}\right){ }^{25}$

Hence the strategic effect captures how strongly pipeline player 2's investment can induce LNG player 1 to cut back output in their common market $B$. This raises its marginal return to installing an additional pipeline capacity in Stage 1, and plays a central role in the results of this paper.

Summary of the equilibrium. Lemma 2 derives the equilibrium values $\left(\widehat{\mathbf{K}}, \hat{x}_{1}, \hat{y}_{1}, \hat{y}_{2}\right)$, together with parameter conditions that ensure that: (i) there is an interior solution for each choice variable, and (ii) it is indeed optimal for both strategic players to produce up to installed capacity in Stage 2 .

Lemma 2. Assume that the following parameter conditions are satisfied: in market A, (i) $b x_{f}<\left(a-r_{1}-c_{1}^{A}\right)$ and in market $B$ (ii) $\beta y_{f}<\min \left\{\frac{\left[(2-\sigma) \phi_{1}-\phi_{2}\right]}{(1-\sigma)},\left(2 \phi_{2}-\phi_{1}\right)\right\}$ and (iii) $r_{2}>\left(\frac{\sigma}{3-2 \sigma}\right)\left(2 \phi_{2}-\phi_{1}\right)$. The equilibrium in capacity investments and sales volumes is given by:

$$
\begin{aligned}
& \hat{x}_{1}=x_{m} \equiv \frac{\left(a-r_{1}-c_{1}^{A}-b x_{f}\right)}{2 b} \\
& \hat{y}_{1}=\frac{\left[(2-\sigma) \phi_{1}-\phi_{2}\right]-(1-\sigma) \beta y_{f}}{\beta(3-2 \sigma)} \\
& \widehat{K}_{1}=\hat{x}_{1}+\hat{y}_{1} \\
& \widehat{K}_{2}=\hat{y}_{2}=\frac{\left(2 \phi_{2}-\phi_{1}\right)-\beta y_{f}}{\beta(3-2 \sigma)},
\end{aligned}
$$

where the strategic effect $\sigma \in\left(0, \frac{1}{2}\right)$ is given by Lemma 1 .

Equilibrium prices follow as $\hat{p}^{A}=p^{A}\left(\hat{x}_{1} ; x_{f}\right)$ and $\hat{p}_{j}^{B}=p_{j}^{B}\left(\hat{y}_{1}, \hat{y}_{2} ; y_{f}\right)(j=1,2)$.

The first two parts of the parameter conditions ensure interior solutions. Part (i) means that the competitive fringe in market $A$ is not too large to squeeze player 1, as its residual monopolist, entirely out of the market. Similarly, part (ii) means that the fringe in market $B$ is not too large such that both players are active; this also requires that their profitability indices are not too different, that is, neither strategic player has an overly strong cost or demand advantage over the other. Part (iii) ensures that the pipeline player finds it optimal, in Stage 2, to produce up to its installed capacity level; this always holds as long as its investment cost is not too small.

25. There is no direct relationship between the strategic effect and the price elasticities of demand in markets $A$ and $B$; for example, varying $A$ and $B$ 's demand intercepts ( $a$ in $A$ and/or $\alpha_{1}, \alpha_{2}$ in $B$ ) will generally change the demand elasticities - but this has no impact on the strategic effect. 
It is useful to illustrate a couple of cases in which the conditions for market $B$ are met for all possible values of the strategic effect $\sigma \in\left(0, \frac{1}{2}\right)$. First, suppose the strategic players have symmetric costs, $c_{1}^{B}=c_{2}^{B}=c$ and $r_{1}=r_{2}=r$, as well as symmetric demand in market $B, \alpha_{1}=\alpha_{2}=\alpha$ (so that $\left.\phi_{1}=\phi_{2}\right)$; then fringe supply in market $B$ must satisfy $y_{f}<\phi / \beta$ and the investment cost $r>\frac{1}{5}(\alpha-c)$. Second, suppose that players are sufficiently similar in that $\phi_{1} / \phi_{2} \in\left(\frac{2}{3}, 2\right)$; then the conditions boil down to $y_{f}<\left[\min \left\{\phi_{1}+2\left(\phi_{1}-\phi_{2}\right), \phi_{1}-2\left(\phi_{1}-\phi_{2}\right)\right\}\right] / \beta$ for fringe supply and $r_{2}>\frac{1}{4}\left(\alpha_{2}-c_{2}\right)$ for the the pipeline's investment cost.

\section{THE STRATEGIC ADVANTAGE OF PIPELINE GAS OVER LNG}

This section develops the main equilibrium results of the paper. The key to them lies in the asymmetry discussed at the outset: LNG is mobile while pipelines are not.

In the model, the pipeline supplier recognizes that its multimarket LNG rival has an alternative use for its capacity in market $A$ - and can therefore be induced in Stage 2 to cede market share of the common market $B$. This logic operates in an asymmetric fashion: the pipeline player has no such "outside option" for its capacity because its investment is specific to market $B$. That is, the strategic weakness of LNG that arises from its ability to diversify sales across several markets is exploited via the commitment of pipeline gas to serving a single market. This leads to "overinvestment" : the pipeline supplier 2 expands capacity beyond the point where marginal revenue equals long-run marginal cost (so that $M R_{2}^{B}<r_{2}+c_{2}$ ). The strategic effect $\sigma$ captures the strength of this single-market commitment.

Letting $\hat{s}_{j} \equiv \hat{y}_{j} /\left(\hat{y}_{1}+\hat{y}_{2}+y_{f}\right)$ denote player $j$ 's equilibrium market share and $\widehat{\Pi}_{j}^{B}$ its profits in market $B$, leads to the main first result:

Proposition 1. In equilibrium, in the common market $B$ :

(a) the pipeline player's 2 's market share $\hat{s}_{2}$ and profits $\hat{\Pi}_{2}^{B}$ rise with the strategic effect $\sigma$, while the LNG player 1 's market share $\hat{s}_{1}$ and profits $\widehat{\Pi}_{1}^{B}$ fall; (b) both players 'market prices $\hat{p}_{j}^{B}(j=1,2)$ decline with $\sigma$.

Proposition 1 formalizes the idea that a pipeline supplier has a strategic advantage over a multimarket LNG rival in their common export markets. Its single-market commitment enables aggressive overinvestment which makes the pipeline supplier gain market share and profits over its LNG rival in common markets. Conversely, the additional capacity investment means that total output in market $B$ rises — so that the market price and local consumers are better off. ${ }^{26}$

The role taken by the pipeline player is similar to that of a textbook Stackelberg leader. The difference is that players' choices are here made simultaneously rather than sequentially, so the advantage is due to an asymmetry in the market-specificity of technologies rather than the asynchronous timing of moves. In contrast to much of the industrial-organization literature on commitment, neither firm is "the incumbent".

The degree of competition in market $B$ thus lies between perfect competition and the standard Cournot-Nash solution (for output choices in Stage 2, which is nested by Lemma 2 where $\sigma \equiv 0$ ). This is consistent with the simulation results of large-scale models of the European gas market, see, e.g., Egging, Gabriel, Holz and Zhuang (2008). The Cournot equilibrium would here arise if two pipeline suppliers, both solely selling to market $B$, were competing against one another.

26. Formally, this analysis extends the industrial-organization results of Shelegia (2012, Proposition 3) to settings in which players have heterogeneous cost structures and demand conditions can vary across markets. 
Implications for understanding competition between piped gas and LNG in Europe. Proposition 1(a) shows how Gazprom's traditional "dependency" on the European market can be a source of strength - not necessarily a weakness, as is usually claimed in energy-policy discussions. By contrast, the flexibility of LNG to choose between different export markets also creates a strategic vulnerability. This provides a different perspective on the widely-discussed role of Qatari LNG as the "swing producer" between Asia and Europe.

Proposition 1(b) then suggests how European gas customers can benefit from Gazprom having a "high" market share (for a given number of players competing in the market). Its strategic overinvestment raises the intensity of competition in the European market; total gas consumption rises and becomes cheaper. The "quasi-Stackelberg" logic means that a high Gazprom market share can go hand-in-hand with lower prices. This suggests that some caution is needed in drawing inferences about consumer welfare from Gazprom's observed market share, and also that putting a cap on its allowable market share may sometimes be a counterproductive policy measure.

In sum, the model suggests that Gazprom enjoys two sources of competitive advantage over Qatar in the European market. First, industry estimates suggest that Gazprom has significantly lower overall unit costs of supplying the European market than Qatar and other LNG suppliers, including US LNG exports (e.g., IEA, 2009: pp. 481-485; Henderson, 2016). In the model, this leads to a standard efficiency-based advantage in terms of market share and profits. Second, magnifying the cost argument, it enjoys the strategic advantage identified here.

The same argument also applies more broadly to competition between piped gas and LNG. As discussed in Section 2, pipeline connections to end-consumer markets are typically preferable, from a cost perspective, for relatively short distances whereas LNG is more economical for long distances (Jensen, 2004). Thus, for an export market served by both producer types, LNG imports tend to come from further away-with higher transportation costs. Hence pipeline suppliers typically have a cost advantage over LNG rivals selling to the same market.

\section{Implications for "security of supply" analysis and understanding buyer diversification strate-} gies. The analysis also sheds new light on concerns of security of supply and on the diversification strategies pursued by gas buyers. The Herfindahl index of import concentration $H \equiv_{j} s_{j}^{2}$ is a standard metric to quantify supply security and to capture how it varies across importing countries (e.g., European Commission 2014). The underlying idea is that supply security is worse when the Herfindahl index is higher-which is associated with the presence of fewer and/or larger suppliers.

The present modelling shows that, contrary to this conventional wisdom, a higher Herfindahl index of gas-import concentration can be good for consumers. Supposing that fringe suppliers are individually small (so their impact on market concentration is negligible), the equilibrium Herfindahl index for market $B$ is $\widehat{H}(\sigma) \simeq \hat{s}_{1}^{2}(\sigma)+\hat{s}_{2}^{2}(\sigma){ }^{27}$

This leads to the following result:

Proposition 2. In equilibrium, in the common market B, if pipeline player 2 has a higher profitability index than than $L N G$ player $1, \phi_{2} \geq \phi_{1}$ (e.g., symmetric demand $\alpha_{1}=\alpha_{2}$ and lower unit costs $\left.r_{2}+c_{2}^{B} \leq r_{1}+c_{1}^{B}\right)$, then the Herfindahl index $\widehat{H}$ rises with the strategic effect $\sigma$, while this makes consumers better off with lower market prices $\hat{p}_{j}^{B}(j=1,2)$.

27. More formally, let the supply $y_{f}$ of the competitive fringe in market $B$ consist of $m^{B}$ identical firms each supplying $y_{f} / m^{B}$ units. They are individually small, relative to the market as a whole, if either $y_{f}$ is "small" or $m^{B}$ is "large", in which case their overall impact on market concentration is negligible. To illustrate, if the competitive fringe has a total share of say $30 \%$, split equally among $m^{B}=10$ firms, this adds less than 0.01 to the Herfindahl index. 
Proposition 2 highlights a limitation to the common practice of using Herfindahl concentration indices as an inverse measure of "security of supply" in energy markets. Applied to the European energy policy context, the point is that high or increased levels of country-level or regional Herfindahl import indices - for example, due to Gazprom's market share — are not necessarily bad news for consumers.

To understand the result, note if the pipeline supplier has lower costs than its LNG rival, then it must have a larger market share. But since a higher strategic effect further raises its market share - and so the Herfindahl index of concentration also rises. At the same time, by Proposition 1(b), consumers are better off. Thus it is entirely possible for the Herfindahl index and consumer welfare to move in the same direction. In this sense, a higher Herfindahl index may be good for energy security.

It is useful to contrast this with the standard industrial-economics theory on industry concentration. In Cournot-style models, the Herfindahl index and firms' average price-cost margins are positively related (see, e.g., Tirole (1988, Section 5.5)). This result applies when varying industry concentration for a given underlying intensity of competition. By contrast, in the present model, the overinvestment logic leads to an endogenous change in the intensity of competition - which in turn is what drives the change in Herfindahl index. Put simply, not only does industry concentration change, also "Cournot becomes more like Stackelberg". This illustrates how the details of the competitive context are important for properly interpreting market-share measures of supply security.

The model can also help explain why gas-importing countries place significant emphasis on access to LNG supplies. When Lithuania in late 2014 opened the Klaipeda LNG import terminal (a floating storage regasification unit, known as FSRU) this for the first time created direct competition to piped gas from Russia - and reports suggested that it induced a larger-than-expected price concession from Gazprom..$^{28}$ In the model, all else equal, an individual gas-importing country is better off with an import mix of one each of pipeline and LNG supply (such that $\sigma>0$ ) than it would be with two dedicated pipeline suppliers (which corresponds to $\sigma \equiv 0$ ).

The LNG exporter creates an additional competitive externality on the pipeline supplier, making it compete more aggressively. This reduces the import price more strongly than if it were competing against another pipeline rival. For example, if all suppliers have identical costs, the price reduction can be up to $50 \%$ greater due to the strategic effect. For the same reason, it can also be desirable for a country to diversify into LNG imports even if these have higher costs than pipeline supplies.

Implications for understanding competitive dynamics in the European gas market. The present model gives a nuanced perspective on how the strategic players optimally react in different ways to a change in market conditions. Specifically, what are the impacts of a larger competitive fringe $y_{f}$ supplying Europe (market $B$ )?

To answer this question, con- sider the comparative static of how a change in the fringe size $d y_{f}>0$ affects the equilibrium values $\left(\widehat{\mathbf{K}}, \hat{x}_{1}, \hat{y}_{1}, \hat{y}_{2}\right)$. It is necessary to distinguish between two cases. First, in the short run, players' capacity levels remain fixed at the levels that were optimal before the change $d y_{f}>0$ occurs (" $\widehat{K}_{j}$ fixed", $\left.j=1,2\right)$. Second, over the longer run, players reoptimize their capacity levels to be optimal in light of the changed size of fringe supply (" $\widehat{K}_{j}$ optimal", $j=1,2$ ).

The following result shows the competitive responses of pipeline gas vs LNG:

28. See, e.g., "How Lithuania is Kicking Russia to the Curbs" (Forbes, 18 October 2015). 
Proposition 3. In response to an increase in the size of the competitive fringe $d y_{f}>0$ in the common market $B$ :

(a) In the short run (with fixed capacities), pipeline player 2 does not vary its output level while LNG player 1 redirects some output to its other market A, with

$$
\begin{aligned}
& \left.\frac{\partial \hat{y}_{1}}{\partial y_{f}}\right|_{\hat{K}_{1} \text { fixed }}=-\sigma<\left.\frac{\partial \hat{y}_{2}}{\partial y_{f}}\right|_{\hat{K}_{2} \text { fixed }}=0 \\
& \text { as well as }\left.\frac{\partial \hat{x}_{1}}{\partial y_{f}}\right|_{\hat{K}_{1} \text { fixed }}=\sigma \text { in market } A ;
\end{aligned}
$$

(b) In the longer run (with re-optimized capacities), pipeline player 2 reduces output more strongly than $L N G$ player 1, with

$$
\begin{aligned}
& \left.\frac{\partial \hat{y}_{2}}{\partial y_{f}}\right|_{\hat{K}_{2} \text { optimal }}=-\frac{1}{(3-2 \sigma)}<\left.\frac{\partial \hat{y}_{1}}{\partial y_{f}}\right|_{\hat{K}_{1} \text { optimal }}=-\frac{(1-\sigma)}{(3-2 \sigma)}<0, \\
& \text { while }\left.\frac{\partial \hat{x}_{1}}{\partial y_{f}}\right|_{\hat{K}_{1} \text { optimal }}=0 \text { in market } A .
\end{aligned}
$$

Proposition 3 highlights a reversal: in the short run, LNG partially accommodates the growth in fringe supply in market $B$ by diverting sales to market $A$; by contrast, over the longer run, both LNG and piped gas partially accommodate fringe growth — but the pipeline supplier now does so more strongly.

To understand Proposition 3(a), recall that the LNG player's short-term sales strategy is driven by (1), that is, equalizing marginal returns across its two markets. Now observe that an increase in fringe supply has exactly the same impact on its marginal revenue in market $B$ as an increase in its pipeline rival's supply. Therefore, given its capacity investment, its response $\left(\partial \hat{y}_{1} / \partial y_{f}\right)_{\hat{K}_{1} \text { fixed }}$ at the margin is to cut sales by exactly the same magnitude as the strategic effect $\sigma \equiv\left(-\partial y_{1} / \partial K_{2}\right)$ from Lemma 1. Moreover, given that its global sales are at capacity, it follows that the displaced sales of market $B$ reappear in market $A$. Finally, the pipeline player remains inert because it, by assumption, sells at its pre-installed capacity.

The intuition for Proposition 3(b) is that the pipeline player's investment decision-again, due to the strategic effect-is more sensitive to market conditions than the LNG player's. This is what drove the previous "overinvestment" logic in terms of the level of capacity investment, and it here drives "overaccommodation" in terms of the change in its investment. By contrast, in the standard Cournot-Nash case $(\sigma \equiv 0)$, the two strategic players would over the longer run equally accommodate a larger fringe as they then have identically-shaped marginal revenue curves.

Consistent with intuition, the combined degree of accommodation by both strategic players is greater over the longer run than in the short term. To see this, observe that, in the short run, $-\left[\left(\partial \hat{y}_{1} / \partial y_{f}\right)+\left(\partial \hat{y}_{2} / \partial y_{f}\right)\right]_{\hat{K}_{1}, \hat{K}_{2} \text { fixed }}=\sigma \in\left(0, \frac{1}{2}\right)$ while, over the long run, $-\left[\left(\partial \hat{y}_{1} / \partial y_{f}\right)+\left(\partial \hat{y}_{2} / \partial y_{f}\right)\right]_{\hat{K}_{1}, \hat{K}_{2} \text { optimal }}=(2-\sigma) /(3-2 \sigma) \in\left(\frac{2}{3}, \frac{3}{4}\right)$. Hence the long-run adjustment is at least $33 \%$ greater than in the short term - and possibly much greater than that. The flipside of this is that more fringe supply in market $B$ causes a larger reduction in market prices $\left(\hat{p}_{1}^{B}, \hat{p}_{2}^{B}\right)$ in the short term, before the strategic players can fully adjust their decision-making. 
Notice how the global capacity of LNG leads to international spillovers. In the short run, more fringe supply in market $B$ reduces prices in both markets $A$ and $B$ because it causes diversion of LNG cargos from $B$ to $A$. For example, additional small LNG projects serving Europe free up incumbent cargos - which instead go to Asia and benefit consumers there. In the long run, however, as players reoptimize, the price in market $A$ is again determined solely by local market fundamentals (which are unchanged, by assumption). Hence the spillover effect here is only temporary. ${ }^{29}$

In sum, the model is consistent with idea that, over time, Gazprom does more than a large LNG player to accommodate growth of smaller suppliers to Europe.

What determines the magnitude of the strategic effect? Recalling from Lemma 1 that $\sigma=\frac{1}{2}[\beta /(\beta+b)] \in\left(0, \frac{1}{2}\right)$, its strength depends on the ratio $b / \beta$. This is a measure of the relative sizes of markets $A$ and $B$, in form of the ratio of the slopes of their respective demand curves. Larger $\beta$, all else equal, corresponds to a smaller common market $B$; LNG player 1 then finds it less attractive - and is more easily induced to redirect output away from it, so $\sigma$ is larger. Conversely, with smaller $b$, the price in its other market $A$ drops less in response to higher sales - so this also favours redirection and $\sigma$ is larger. (Hence, the comparative statics on $\sigma$ from Propositions 1-2 can be thought of as being driven by changes in market $A$, leaving everything else in market $B$ unchanged.)

In sum, the strategic effect is larger, making European gas buyers and Gazprom better off, when the Asian LNG market is larger relative to Europe. Intuitively, a more attractive outside option in Asia makes it easier for Gazprom to displace LNG in Europe.

\section{ILLUSTRATIVE CALIBRATION TO MARKET DATA}

This section presents an illustrative calibration of the model to global gas market data which shows how the impacts of the strategic effect arising from the asymmetry between piped gas and LNG can be quantitatively significant.

The calibration exercise has three main features. First, it is designed to closely match the observed market data on trade movements in the European and Asia gas markets. Second, it uses the calibration of observed trade quantities to back out the implied unobserved strategic effect; this, in turn, allows a counterfactual exercise of comparing the market outcome in Europe with what would otherwise have obtained under the standard Cournot-Nash solution. Third, it derives the natural gas prices that, in equilibrium, deliver the calibrated trade quantities.

Input data. The calibration employs 2014 full-year data on gas trade movements from BP (2015). The model equilibrium, as characterized by Lemma 2, is a long-run market equilibrium; in practice, markets are usually in a state of flux, often driven by large short-term shocks. This choice of calibration date, on one hand, leaves several years for the market to adjust to the 2011 Fukushima disaster; on the other hand, it precedes the ramp-up of new LNG export projects in the US and Australia.

The move from theory to empirical application goes as follows. The two markets are Asia (market $A$ ) and Europe (market $B$ ), which together account for over $70 \%$ of global gas trade. The two strategic players are Qatar as LNG player 1 and Russia/Gazprom is pipeline player 2. The two markets account for the bulk of both players' global sales. Each market has a competitive fringe, which is made up of all other LNG and pipeline gas suppliers. The competitive fringes include within-region trade movements such as supply from Norway and The Netherlands in Europe. As fringe suppliers are exogenous to the model, the values for $x_{f}$ (Asia) and $y_{f}$ (Europe) are set to match

29. In the present model, there are no international spillover effects from a change in the size of the competitive fringe $y_{f}$ in market $A$. 
observed data. Columns (i) and (iii) in Table 1 summarize the observed quantities and prices in Asia and Europe.

Table 1: Model calibration and counterfactual results

\begin{tabular}{|c|c|c|c|c|c|}
\hline & \multicolumn{2}{|c|}{ Asia } & \multicolumn{3}{|c|}{ Europe } \\
\hline & $\begin{array}{c}\text { (i) } \\
\text { Observed } \\
\text { BP (2015) }\end{array}$ & $\begin{array}{c}\text { (ii) } \\
\text { Calibrated } \\
\text { equilibrium }\end{array}$ & $\begin{array}{c}\text { (iii) } \\
\text { Observed } \\
\text { BP (2015) }\end{array}$ & $\begin{array}{c}\text { (iv) } \\
\text { Calibrated } \\
\text { equilibrium } \\
\left(\sigma=\frac{1}{6}\right)\end{array}$ & $\begin{array}{c}(\mathrm{v}) \\
\text { Cournot-Nash } \\
\text { counterfactual } \\
(\sigma=0)\end{array}$ \\
\hline Qatar & 74.4 & 74.8 & 23.6 & 24.1 & 32.4 \\
\hline Russia & 0 & 0 & 147.7 & 149.0 & 132.4 \\
\hline Fringe & 220.4 & 220.4 & 242.7 & 242.7 & 242.7 \\
\hline Price & $\$ 16.33$ & $\$ 11.24$ & $\$ 8.67$ & $\$ 8.10$ & $\$ 8.31$ \\
\hline
\end{tabular}

Notes: Quantities are in bcm of natural gas; prices are in US\$ per mmbtu. For Asia (market $A$ ), supplied quantities correspond in the model to Qatar $\left(x_{1}\right)$, Russia (N/A), and competitive fringe $\left(x_{f}\right)$ while the market price is $p^{A}$. For Europe (market $B$ ), supplied quantities correspond to Qatar $\left(y_{1}\right)$, Russia $\left(y_{2}\right)$, and competitive fringe $\left(y_{f}\right)$ while the market price is $p^{B}$.

On the cost side, the strategic players' long-run marginal costs are assumed to be, respectively, $r_{1}+c_{1}^{A}=r_{1}+c_{1}^{B}=\$ 7 \frac{1}{2} / \mathrm{mmbtu}$ and $r_{2}+c_{2}^{B}=\$ 5 / \mathrm{mmbtu}$. This reflects (i) similar shipping costs for Qatari LNG in serving Asia and Europe $\left(c_{1}^{A} \simeq c_{1}^{B}\right.$, see Ritz 2014), and (ii) Gazprom's cost advantage over LNG in Europe. ${ }^{30}$

On the demand side, calibrated demand parameters for Asia (market $A$ ) are an intercept $a=\$ 26 / \mathrm{mmbtu}$ and a slope $b=\frac{1}{20}$, which also converts price into quantity units of bcm/year. For Europe (market $B$ ), the parameters are $\alpha_{j}=\$ 18 \frac{1}{2} / \mathrm{mmbtu}$ (for $j=1,2$ ) while $\beta=\frac{1}{40} .{ }^{31}$ These parameters reflect that (1) the maximum willingness-to-pay is higher in Asia than in Europe ( $a$ exceeds $\alpha$ ), and (2) the maximum size of the European market is nonetheless larger $(\alpha / \beta$ exceeds $a / b)$. This allows the model to deliver higher prices in Asia alongside higher quantities in Europe.

Calibrated equilibrium. Using Lemma 1, The demand-side parameters immediately pin down the strategic effect as $\sigma=\frac{1}{6}$. It is clear that parts (i) and (ii) of the parameter condition from Lemma 2 must be met because fringe supplies $x_{f}, y_{f}$ do not crowd the strategic players entirely out of either market; part (iii) requires that the capital cost of Russia (player 2) satisfies $r_{2}>\$ 1 / \mathrm{mmbtu}$.

Using Lemma 2, columns (ii) and (iv) of Table 1 show the calibrated quantities and prices for both markets. In terms of quantities, the calibration delivers a close match with the observed data; the deviations are less than $2.5 \%$ for the strategic players across both markets. In terms of prices, the calibration fairly closely matches the European price with a deviation of less than $10 \%$. It underestimates the Asian price: the calibrated "Asian premium" is 39\%, in line with the historical

30. These cost figures are illustrative but broadly in line with estimates in the existing literature - with the caveat that these show considerable variation and can be difficult to compare to one another in terms of methodology. JP Morgan (2017) estimates short-run marginal production costs at $\$ 1.5$ for Russian piped gas, $\$ 3.0$ for Qatar's LNG and above $\$ 4.0$ for other LNG exporters such as the US and Australia. Henderson (2016) has Gazprom's long-run marginal cost below \$6 while Henderson and Sharples (2018) estimate the marginal cost of US LNG exports to Europe at \$4.3 (short run) and \$7-10 (long run). These are likely an upper bound for Qatar which is widely seen as the lowest-cost LNG (Fattouh, Rogers and Stewart, 2015). (Cost estimates used in the academic literature sometimes date back to the 2000s, making comparisons with newer industry sources difficult.)

31. For simplicity, this assumes that Qatari LNG and Russian piped gas are perfect substitutes in the eyes of consumers, $\alpha_{1}=\alpha_{2}=\alpha$. 
average but significantly less than the actual 2014 price differential of $88 \%$. In this sense, the model appears to underestimate the degree of market power especially in Asia, at least in this period. ${ }^{32}$

Counterfactual analysis. Column (v) of Table 1 reports the counterfactual of a Cournot-Nash equilibrium in Europe, obtained by setting the strategic effect $\sigma=0$ and keeping everything else unchanged (including fringe supply to Europe). ${ }^{33}$ Comparison with the calibrated equilibrium in column (iv) confirms the qualitative comparative statics from Propositions 1 and 2 and illustrates the quantitative impact of the strategic effect: it raises Russia's market share by $3.3 \%$ and reduces the market price by $2.5 \%$ (Proposition 1 ) and the Herfindahl index for the strategic players rises by $17.7 \%$ from $\widehat{H}(\sigma=0)=1119$ under Cournot-Nash to $\widehat{H}\left(\sigma=\frac{1}{6}\right)=1317$ in the calibrated equilibrium (Proposition 2). This is driven by "overinvestment" in pipeline capacity, at $12.5 \%$ above the Cournot-Nash level. This, in turn, is driven by the ability of its single-market commitment to gain share from its multimarket LNG rival.

\section{ROBUSTNESS OF THE RESULTS}

The above model was deliberately kept simple to bring out the underlying intuition as clearly as possible. This section explains why its results are considerably more general.

1. Regional price differentials. The existence of an "Asia premium", as discussed in Section 2, has been a central feature of global gas pricing in recent decades. This was also one of the results of the numerical illustration in Section 6. Yet it is worth emphasizing that neither the strategic effect $\sigma$ nor any of Propositions 1-3 hinge on one of the markets having a higher price than the other, i.e., the sign or magnitude of the price differentials $\left[\hat{p}^{A}-\hat{p}_{j}^{B}\right](j=1,2$ in market $B)$. So the results are robust to whether or not regional prices are indeed higher in Asia than Europe.

2. Non-linear demand structures. The analysis has assumed, for simplicity, that the demand curves in both markets $A$ and $B$ are linear. Such linear-demand assumptions are widespread in the gas-markets literature; they are not necessary for any of the present results but do help simplify the exposition. In the common market $B$, the key feature is that competition is in strategic substitutes; this is what generates a positive strategic effect $\sigma \equiv\left(-\partial y_{1} / \partial K_{2}\right)>0$. It is well-known that this feature of competition also often applies in oligopoly models with non-linear demand structures (see, e.g., Bulow, Geneakoplos \& Klemperer, 1985; Tirole, 1988; Shelegia, 2012). Similarly, allowing the LNG player 1 to instead face a non-linear demand curve in market $A$ can strengthen or weaken the strategic effect-but does not overturn its existence.

3. Player rationality and multimarket exposure. It is also worth noting that the multimarket LNG player is not acting irrationally by operating in both markets. Its profitability in market $B$ may be lower than that of its pipeline rival—but it can nonetheless be profit-maximizing for both players to self-select respectively into these "diversified" and "focused" structures. For LNG player 1, serving both markets $A$ and $B$ is more profitable than serving only market $B$ whenever the profit contribution

32. The equilibrium values of the price elasticity of demand, at the market level, are -.76 in Asia and -.78 in Europe. These values are broadly in line with existing literature that finds inelastic demand for natural gas. (Of course, the price elasiticies at the firm level, exceed unity for all strategic players in all markets.) This also shows that the large differences in competition and prices between Asia and Europe are not necessarily driven, at equilibrium, by differences in their demand elasticities.

33. In market $B$, existing fringe supplies would continue to supply given that the counterfactual Cournot-Nash price exceeds the observed price; the substantive assumption here is that the higher price does not bring forward more fringe supply. In market $A$, there is no change in the market price so the incentives for fringe supply remain unchanged. 
of $A$ exceeds the adverse impact on profits from $B$. Similarly, it may be too expensive (or infeasible) for the pipeline player 2 to make another investment to enter market $A$, e.g., due to the geographic location of its resource base. That is, player 2's cost structure is too high, relative to demand $p^{A}(\cdot)$, to allow for profitable entry into market $A$.

4. Geopolitics. Political considerations, as discussed in Section 2, play an important role in the natural gas industry - but they are also difficult to formalize. The above model assumes that the strategic players are profit-maximizers. This is a canonical assumption in economics, also made by large-scale gas market models. Yet it is perhaps less clear how applicable it really is for players that are state-controlled. For example, these may have a preference for running a larger operation than would be strictly profit-maximizing - to help gain political power, in form of greater geopolitical influence or of the domestic political clout that comes with a larger export business.

It turns out that the main insights are not overly sensitive to the profit-maximization assumption; the strategic players can, more generally, be thought of as utility-maximizers. Consider the single-market player 2 and suppose that it instead maximizes $U_{2}=\Pi_{2}^{B}+\rho_{2}^{B} y_{2}$ where $\rho_{2}^{B} \geq 0$ is a parameter that measures the degree of political objective associated with "bigness" . In Stage 2, by assumption, player 2 still produces up to its installed capacity - but how does the political objective affect its investment decision in Stage 1? It is not difficult to check that its first-order condition, akin to (5) above, becomes $M R_{2}^{B}+\beta \sigma y_{2}+\rho_{2}=r_{2}+c_{2}^{B}$. This makes clear how the strategic effect and the political objective have similar consequences: they both inflate 2's marginal return on investment and thus lead to "overinvestment" (relative to the standard profit-maximizing Cournot-Nash case). Importantly, however, note the strategic effect $\sigma$ itself remains exactly as in Lemma 1 as its magnitude is driven by player 1's decision-making not player 2's.

Now suppose that the multi-market player 1 instead maximizes $U_{1}=\Pi_{1}^{A}+\rho_{1}^{A} x_{1}+\Pi_{1}^{B}+\rho_{1}^{B} y_{1}$ where $\rho_{1}^{i} \geq 0(i=A, B)$ allows its political objectives to vary between markets. In Stage 2, maximization now implies equating marginal utility across the two markets, akin to (1) above, with $M R_{1}^{A}\left(K_{1}-y_{1} ; x_{f}\right)+\rho_{1}^{A}-c_{1}^{A}=M R_{1}^{B}\left(y_{1}, K_{2} ; y_{f}\right)+\rho_{1}^{B}-c_{1}^{B}$. Insofar as the political objective varies across markets, this "distorts" player 1 's sales strategy towards the politically more valuable market. However, the crucial point is that the strategic effect $\sigma$, which is driven solely by slopes of $M R_{1}^{A}$ and $M R_{1}^{B}$ (not by their levels and hence not by $\left(\rho_{1}^{A}, \rho_{1}^{B}\right)$ ) again remains exactly as in Lemma 1.

These arguments suggest that, at least across a range of alternative specifications, the main insights are robust to the inclusion of political objectives. In short, it is more important that the strategic players maximize than what exactly is being maximized.

5. The degree of vertical integration by strategic players. For concreteness, the model was introduced based on vertical integration, for both the LNG and pipeline player, between the upstream and midstream stages of their respective value chains. Yet, as discussed in Section 2, in practice there is considerable variation in the degree of vertical integration; some LNG players are not backward-integrated into extraction of natural gas while others are also forward-integrated into LNG regasification.

It turns out that the model admits different interpretations on the degree of vertical integration. For instance, if the LNG player is not backward-integrated, then this changes the meaning of its capital investment $K_{1}$ in Stage 1. This, in turn, affects the relative sizes of the unit cost of investment $\left(r_{1}\right)$ and the subsequent production costs $\left(c_{1}^{A}, c_{1}^{B}\right)$. More generally, the allocation between investment and production costs will vary depending on what each players "owns" versus "buys" (from third parties). The key point is that the results from Propositions 1-3, as such, do not hinge on a particular definition of capital or on the precise relationship between $\left(r_{1}, c_{1}^{A}, c_{1}^{B}\right)$ and $\left(r_{2}, c_{2}^{B}\right)$ in the strategic players' cost structures. In that sense, the results do not depend on the precise degree 
of vertical integration (subject to the parameter condition from Lemma 2 being met). However, it would certainly be interesting for future research to endogenize the choice of vertical integration.

6. Multiple strategic pipeline gas or LNG players. To bring out the results as clearly as possible, this paper considers a model with only two strategic players. In practice, there are other gas suppliers with substantial market shares that may also have a degree of pricing power; for example, this might include Equinor (Norway) in Europe.

Yet the simple setup does not seem critical for its insights to hold. To begin with, none of Propositions 1-3 depend on the sizes of the competitive fringes $\left(x_{f}, y_{f}\right)$ in the two markets; therefore varying fringe supply relative to the strategic players' sales to each market already allows for a flexible range of market structures to be represented. The economic logic of the LNG player equalizing marginal revenues across markets — and its resulting strategic vulnerability remains.

Richer market structures quickly make the model unwieldy but its main insights appear to be generalizable. For example, with additional pipeline players supplying market $B$, all would vie to exploit the multimarket exposure of their LNG rival(s). In a recent industrial-organization paper, Arie, Markovic and Varela (2017) make progress in this direction in a model that allows for $n \geq 2$ strategic players but restricts attention to symmetric cost structures. Nonetheless, it would clearly be useful for future research to try to further extend the model in these directions.

7. Strategic preemption of LNG by pipeline gas. The analysis focuses on an interior solution in which the multimarket LNG player finds it optimal to serve both markets $A$ and $B$. This case is of primary interest because it reflects the observed market reality of Qatari LNG (as well as other LNG suppliers) choosing to serve both Europe and Asia. As made precise by parameter conditions (i)-(iii) of Lemma 2, the interior solution requires that the LNG player's cost structure is not too inferior relative to its pipeline rival.

More broadly, the analysis suggests the possibility that the single-market player could use its strategic advantage to drive its multimarket rival entirely out of their common market $B$. A key point here is that, due to the existence of strategic effect, the parameter conditions needed for the multi-market player to remain "active" in market $B$ are more stringent than in a standard CournotNash equilibrium $(\sigma \equiv 0)$. That is, it is easier for the pipeline player to drive out of market $B$ an LNG player who also operates in another market than it is to drive out an otherwise identical player who does not have such an outside option. Moreover, it seems reasonable to conjecture that, in a sequential model in which the pipeline player moves first, its strategic advantage would be further exacerbated (relative to the simultaneous-moves equilibrium of Lemma 2), thus also facilitating strategic preemption of LNG rivals.

8. Mitigating the strategic weakness of multimarket flexibility. Finally, the analysis also raises the question of how a multimarket LNG player might mitigate its strategic weakness. For example, it could, already at the investment stage, earmark specific capacity shares to individual markets by signing long-term contracts with local buyers. Then it would no longer have to-or indeed be able to-allocate capacity between markets in Stage 2; in effect, this bundles together the two stages. The multimarket weakness, and the qualitative insights from above, apply as soon as some installed capacity is flexibly allocated between markets in Stage 2 - not necessarily all capacity, as is formally the case in the model. ${ }^{34}$ Such a mix reflects actual industry practice; there are significant flexible

34. The strategic effect, which is based on marginal incentives, is not affected by such capacity pre-allocation. To see why, suppose that player 1 writes contracts that pre-allocate sales of $\left(\bar{x}_{1}, \bar{y}_{1}\right)$ to markets $A$ and $B$ respectively, where $\bar{x}_{1}+\bar{y}_{1}<K_{1}$, and that the remaining $K_{1}-\bar{x}_{1}-\bar{y}_{1}$ units are sold in Stage 2 according to $\left[M R_{1}^{A}\left(x_{1}\right)-c_{1}^{A}\right]=\left[M R_{1}^{B}\left(y_{1}, y_{2}\right)-c_{1}^{B}\right]$, where $x_{1}=\left[K_{1}-\left(\bar{x}_{1}+\bar{y}_{1}\right)-y_{1}\right]$ and $y_{2}=K_{2}$. It is not difficult to check that the strategic effect $\sigma \equiv\left(-\partial y_{1} / \partial K_{2}\right)$ remains ex- 
volumes that LNG producers allocate between export markets - even if long-term contracts still play an important role. ${ }^{35}$

9. Other modelling assumptions. Two maintained assumptions are that: (i) both strategic players' cost structures feature constant unit costs of production and investment, and (ii) both strategic players in Stage 2 produce up to their respective installed capacities. Both assumptions are made to keep the analysis tractable; the first is unlikely to exactly hold in practice but may be a useful approximation while the second, as explained in Section 3, greatly simplifies solving the model (and is optimal for players under parameter condition (iii) of Lemma 2). However it is worth noting that neither assumption is critical for the economic logic of the LNG player equalizing marginal revenues across markets - this applies even under non-constant unit costs and/or production below capacity. So it seems a reasonable conjecture that Propositions 1 and 2 would continue to apply under weaker assumptions - but a formal proof is beyond the scope of this paper.

\section{OBSERVATIONS ON RUSSIAN GAS EXPORT STRATEGY}

While its gas exports have traditionally been dedicated to Europe, Russia has recently moved towards what has been variously described as a "pivot to Asia". The model helps shed light on the strategic issues arising from this evolution of its gas-export strategy.

In May 2014, Russia and China reached agreement on the largest contract in the history of the natural gas industry. ${ }^{36}$ The "Power of Siberia" deal was reported to involve pipeline gas deliveries worth US\$400 billion over a 30-year period commencing in 2018, with China also extending US $\$ 25$ billion of financing to support the development of Eastern Siberian gasfields and pipeline construction. (As of late 2018, it is expected that the Power of Siberia pipeline will begin operations in the second half of 2019.)

At first glance, this eastward diversification of Russian gas exports may appear puzzling in light of the preceding game-theoretic analysis. In particular, it seems to turn Russia into a multimarket exporter to both Europe and Asia - and thus expose her to the same strategic vulnerability of LNG exporters. On closer inspection, however, it turns out that this conclusion does not follow. The key point is the Power of Siberia project involves natural gas in Eastern Siberia that was previously "stranded" and will become dedicated to the Chinese market. Hence the above concerns over strategic weakness do not apply. In effect, the existing western-bound pipeline (to Europe) and the new eastern-bound pipeline (to Asia) are different capacities, specific to different gas fields, with no scope for redirection into each other's markets.

Particularly interesting in this regard is that, soon thereafter, in November 2014, it was reported that Russia and China were agreeing on a further major gas deal. This "Altai" project is fundamentally different in that it involves pipeline gas from Western Siberia that has so far been going to European consumers. This led to speculation that Russia could indeed become the new

actly as in Lemma 1 . As long as the pre-allocated sales $\left(\bar{x}_{1}, \bar{y}_{1}\right)$ occur at the same prices as the flexible sales $\left(\hat{x}_{1}, \hat{y}_{1}\right)$, this has no impact on payoffs, so does not affect the optimal choice of $K_{1}$. (Implicit in the setup is that transaction costs of long-term contracting prevent player 2 from pre-allocating all of its capacity.)

35. Contracting arrangements have become more flexible over the last decade. Trade in spot and short-term markets now makes up 30\% of global LNG sales (GIIGNL, 2017) — and these were key to the market's response to the 2011 Fukushima accident (IEA, 2016). Brito and Hartley (2007) present a model in which a shift towards spot trading has self-fulfilling properties.

36. The factual background here is based on press reports, especially "Gazprom's China Gas Price Said to be Near German Level" (Bloomberg, 2 June 2014) and "Putin Snubs Europe with Siberian Gas Deal that Bolsters China Ties" (Financial Times, 10 November 2014). 
"swing producer" between European and Asian markets, taking over this role from Qatari LNG. The present analysis suggests that, from a strategic viewpoint, this deal should be significantly less attractive to Russia because it risks undermining Gazprom's position in Europe. Indeed, more recent press reports suggest, for a range of economic and political considerations, this Altai project is no longer being pursued.

The present analysis also points to the possibility that the Power of Siberia project, as a pipeline investment dedicated to the Chinese market, has a strategic incentive to "overinvest" in capacity. This would allow it to gain market share from current (and future) LNG rivals - such as Qatar but also Australian and US LNG export projects - who serve the Chinese market, amongst others. If so, this will intensify competition in the Chinese market, shift market share from LNG to piped gas, and significantly benefit local gas buyers.

It is also worth noting that Russia has, over the last decade, itself been building a presence in LNG - though it remains small at around 5\% of total gas exports. This LNG has come from the Sakhalin-2 project, which has been running since 2009, where Gazprom is partnered with Royal Dutch Shell, Mitsui and Mitsubishi. Again, these LNG exports do not come from the same fields that sell pipeline gas to Europe; in effect, they represent different capacity investments. To date, the project has been selling almost exclusively to Japan and South Korea, in part because transport costs to Europe or Latin America are very high. There is also the Yamal LNG project in the Russian Arctic, which involves different players: Novatek, Total, and CNPC. This project shipped its first gas in late 2017 - and some observers expect it to double Russia's share of the global LNG market over the coming years. ${ }^{37}$

More generally, the above analysis demonstrates that diversification of a traditionally pipeline-based exporter into LNG (from the same gas fields) can come at a strategic cost. So it can be rational for a pipeline seller to reject a seemingly profitable diversification opportunity into LNG so as to protect its existing business.

\section{CONCLUSION}

This paper has presented a new perspective on international trade in the natural gas industry. Its insights are driven by a fundamental asymmetry: LNG is mobile, pipelines are not. Game-theoretic modelling showed how piped gas enjoys a strategic advantage over LNG rivals, developed implications for the analysis of supply security, and helped shed light on the diversification strategies pursued by gas-importing and gas-exporting countries.

This paper has deliberately focused, quite narrowly, on the strategic advantage enjoyed by a firm committed to serving fewer markets than its rivals. In practice, uncertainty over demand and costs (and rival behaviour) can play a significant role in driving decisions. There may be trade-offs between committing to particular investments and retaining flexibility to adjust decisions further down the road (see, e.g., Ghemawat and del Sol 1998). Multimarket LNG players may be better equipped to deal with, and benefit from, such uncertainty.

The analysis presented here opens other avenues for future research. Over the next 5 years, the US looks set to become a major LNG exporter; its cargos have since 2016 already sold to both Europe and Asia. Incorporating this would extend the model to three regions in which the repercussions for competition against Russian piped gas and other LNG exporters could be studied. The present results may also lend themselves to econometric testing, for example, the finding that gas

37. See Henderson (2018) for another perspective on the gas deals between Russia and China, including useful further discussion of Russia's future LNG growth. 
buyers are better off, all else equal, with imports from a mix of piped gas and LNG than being supplied only by pipelines.

Finally, it would be useful to try to integrate the current strategic perspective on competition - via the commitment role of players' capacity investments - into the large-scale simulation models that currently dominate the literature on natural gas markets. This may prove challenging from a technical perspective but it could have substantial payoffs in form of a richer picture of competitive dynamics.

\section{ACKNOWLEDGMENTS}

I thank four referees for their useful and constructive feedback. My thanks are also due to Chi Kong Chyong, Anna Creti, Florian Ederer, James Henderson, Pår Holmberg, Rutger-Jan Lange, Arjun Mahalingam, David Newbery, Pierre Noël, Andy Philpott, Michael Pollitt, Danny Ralph, Thomas Tangerås, and seminar audiences at Stockholm IFN, MIT, Toulouse 2015 Energy \& Climate Change Conference, EAERE 2015 (Helsinki) and Mines ParisTech for helpful comments and discussion. Financial support from the Enel Foundation in the initial stages of this project is gratefully acknowledged. All views expressed and any errors are my responsibility.

\section{REFERENCES}

Arie, Guy, Sarit Markovic, and Mauricio Varela (2017). "On the Competitive Effects of Multimarket Contact." European Economic Review 100: 116-142. https://doi.org/10.1016/j.euroecorev.2017.08.002.

BP (2015). Statistical Review of World Energy 2016. BP plc, London, UK.

Brito, Dagobert L. and Peter R. Hartley (2007). "Expectations and the Evolving World Gas Market.” The Energy Journal 28: 1-24. https://doi.org/10.5547/ISSN0195-6574-EJ-Vol28-No1-1.

Bulow, Jeremy I., John D. Geanakoplos, and Paul D. Klemperer (1985). "Multimarket Oligopoly: Strategic Substitutes and Complements.” Journal of Political Economy 93: 488-511. https://doi.org/10.1086/261312.

Chyong, Chi Kong and Benjamin F. Hobbs (2014). "Strategic Eurasian Natural Gas Market Model for Energy Security and Policy Analysis: Formulation and Application to South Stream.” Energy Economics 44: 198-211. https://doi.org/10.1016/j. eneco.2014.04.006.

Cooper, Thomas E. (1989). "Indirect Competition with Spatial Product Differentiation." Journal of Industrial Economics 37: 241-257. https://doi.org/10.2307/2098613.

Egging, Ruud, Steven A. Gabriel, Franziska Holz, and Jifang Zhuang (2008). “A Complementarity Model for the European Gas Market.” Energy Policy 26: 2385-2414. https://doi.org/10.1016/j.enpol.2008.01.044.

European Commission (2014). "In-Depth Study of European Energy Security." Commission Staff Working Document, SWD(2014) 330 final/3, May 2014.

Fattouh, Bassam, Howard V. Rogers, and Peter Stewart (2015). "The U.S. Shale Gas Revolution and its Impact on Qatar's Position in Gas Markets." Columbia Center on Global Energy Policy, March 2015.

Ghemawat, Pankaj (1991). Commitment: The Dynamic of Strategy. The Free Press.

Ghemawat, Pankaj and Patricio del Sol (1998). "Commitment versus Flexibility.” California Management Review 40: 26 -42. https://doi.org/10.2307/41165963.

GIIGNL (2017). Annual Report: The LNG Industry in 2017. The International Group of Liquefied Natural Gas Importers, Paris, France.

Growitsch, Christian, Harald Hecking, and Timo Panke (2014). "Supply Disruptions and Regional Price Effects in a Spatial Oligopoly_An Application to the Global Gas Market.” Review of International Economics 22: 944-975. https://doi. $\operatorname{org} / 10.1111 /$ roie. 12138 .

Hartley, Peter R. (2015). "The Future of Long-term LNG Contracts.” The Energy Journal 36: 209-233. https://doi. org/10.5547/01956574.36.3.phar.

Hawk, Ashton, Gonçalo Pacheco-de-Almeida, and Bernard Yeung (2013). "Fast-Mover Advantages: Speed Capabilities and Entry into the Emerging Submarket of Atlantic Basin LNG." Strategic Management Journal 34: 1531-1550. https://doi. org/10.1002/smj.2085.

All rights reserved. Copyright (C) 2019 by the IAEE. 
Henderson, James (2016). “Gazprom-Is 2016 the Year for a Change of Pricing Strategy in Europe?” Oxford Institute for Energy Studies, Oxford Energy Comment, January 2016.

Henderson, James (2018). "Russia's Gas Pivot to Asia: Another False Dawn or Ready for Lift Off?” Oxford Institute for Energy Studies, Oxford Energy Insight: 40, November 2018.

Henderson, James and Jack Sharples (2018). “Gazprom in Europe-Two ‘Anis Mirabiles’ but can it continue?” Oxford Institute for Energy Studies, Oxford Energy Insight: 29, March 2018.

Holz, Franziska, Christian von Hirschhausen, and Claudia Kemfert (2008). "A Strategic Model of European Gas Supply (GASMOD).” Energy Economics 30: 766-788. https://doi.org/10.1016/j.eneco.2007.01.018.

IEA (2009). World Energy Outlook 2009. International Energy Agency, Paris, France.

IEA (2016). Global Gas Security Review 2016. International Energy Agency, Paris, France.

IEA (2017). World Energy Outlook 2017. International Energy Agency, Paris, France.

IGU (2013). World LNG Report - 2013 Edition. International Gas Union, Norway.

Jensen, James T. (2004). The Development of a Global LNG Market. Oxford University Press.

Joskow, Paul L. (2013). "Natural Gas: From Shortages to Abundance in the United States." American Economic Review 103: 338-343. https://doi.org/10.1257/aer.103.3.338.

JP Morgan (2017). "Eye on the Market: Energy Outlook 2017.” JP Morgan Private Bank, June 2017.

Li, Raymond, Roselyne Joyeux, and Ronald D. Ripple (2014). “International Natural Gas Market Integration.” The Energy Journal 35: 159-179. https://doi.org/10.5547/01956574.35.4.7.

Makholm, Jeff D. (2012). The Political Economy of Pipelines: A Century of Comparative Institutional Development. University of Chicago Press. https://doi.org/10.7208/chicago/9780226502120.001.0001.

Neumann, Anne, Sophia Rüster, and Christian von Hirschhausen (2015). "Long-Term Contracts in the Natural Gas Industry: Literature Survey and Data on 426 Contracts (1965-2014).” DIW Data Documentation 77, DIW Berlin, February 2015.

Ritz, Robert A. (2014). "Price Discrimination and Limits to Arbitrage: An Analysis of Global LNG Markets." Energy Economics 45: 324-332. https://doi.org/10.1016/j.eneco.2014.07.013.

Shelegia, Sandro (2012). "Is the Competitor of My Competitor Also My Competitor?" Journal of Economics \& Management Strategy 21: 927-963. https://doi.org/10.1111/j.1530-9134.2012.00353.x.

Smeers, Yves (2008). “Gas Models and Three Difficult Objectives.” CORE Discussion paper 2008/9, Université Catholique de Lovain, February 2008.

Smil, Vaclav (2015). Natural Gas: Fuel for the 21st Century. John Wiley \& Sons.

Stern, Jonathan (ed.) (2012). The Pricing of Internationally Traded Natural Gas. Oxford University Press.

Stern, Jonathan and Howard V. Rogers (2014). "The Dynamics of a Liberalised European Gas Market: Key Determinants of Hub Prices, and Roles and Risks of Major Players." Oxford Institute for Energy Studies NG94, December 2014. https://doi. org/10.26889/9781784670184.

Tirole, Jean (1988). The Theory of Industrial Organization. The MIT Press.

Williamson, Oliver (1985). The Economic Institutions of Capitalism. The MIT Press.

Yergin, Daniel (2006). "Ensuring Energy Security.” Foreign Affairs 85: 69-82. https://doi.org/10.2307/20031912.

Yergin, Daniel (2011). The Quest: Energy, Security and the Remaking of the Modern World. Allen Lane.

\section{APPENDIX}

Proof of Lemma 1. Totally differentiating (1) shows that the strategic effect satisfies:

$$
\sigma \equiv\left(-\frac{\partial y_{1}}{\partial K_{2}}\right)=\frac{\frac{\partial M R_{1}^{A}}{\partial K_{2}}-\frac{\partial M R_{1}^{B}}{\partial K_{2}}}{\left(\frac{\partial M R_{1}^{A}}{\partial y_{1}}-\frac{\partial M R_{1}^{B}}{\partial y_{1}}\right)}=\left[\frac{\beta}{2 \beta+2 b}\right] \in\left(0, \frac{1}{2}\right),
$$

The final equality uses that $\partial M R_{1}^{A} / \partial K_{2}=0$ (player 2's actions have no direct impact on revenues in market $A), \partial M R_{1}^{B} / \partial K_{2}=\partial M R_{1}^{B} / \partial y_{2}=-\beta, \partial M R_{1}^{A} / \partial y_{1}=-\partial M R_{1}^{A} / \partial x_{1}=-2 \beta$, as well as $\partial M R_{1}^{B} / \partial y_{1}=-2 b$.

Proof of Lemma 2. Begin by deriving the equilibrium values $\left(\widehat{\mathbf{K}}, \hat{x}_{1}, \hat{y}_{1}, \hat{y}_{2}\right)$, and then determine parameter conditions which ensure that the equilibrium is indeed valid. By arguments in the main text, $\hat{x}_{1}=x_{m}$, 
and, by assumption, $\hat{y}_{2}=\widehat{K}_{2}$. The two remaining unknowns $\left(y_{1}, K_{2}\right)$ are pinned down as follows. First, by (1), $M R_{1}^{B}\left(y_{1}, y_{2} ; y_{f}\right)=r_{1}+c_{1}^{B}$; using $y_{2}=K_{2}$ and $M R_{1}^{B}\left(y_{1}, y_{2} ; y_{f}\right)=p_{1}^{B}-\beta y_{1}=\alpha_{1}-\beta\left(2 y_{1}+K_{2}+y_{f}\right)$ , this can also be written as:

$$
y_{1}=\frac{\phi_{1}-\beta\left(K_{2}+y_{f}\right)}{2 \beta} .
$$

Second, by (5), $M R_{2}^{B}+\beta \sigma y_{2}=r_{2}+c_{2}^{B}$, which using $y_{2}=K_{2}$ gives:

$$
K_{2}=\frac{\phi_{2}-\beta\left(y_{1}+y_{f}\right)}{\beta(2-\sigma)} .
$$

Solving these two equations simultaneously yields:

$$
\hat{y}_{1}=\frac{\left[(2-\sigma) \phi_{1}-\phi_{2}\right]-(1-\sigma) \beta y_{f}}{\beta(3-2 \sigma)} \text { and } \widehat{K}_{2}=\frac{\left(2 \phi_{2}-\phi_{1}\right)-\beta y_{f}}{(3-2 \sigma) \beta}
$$

Confirming $\left(\widehat{\mathbf{K}}, \hat{x}_{1}, \hat{y}_{1}, \hat{y}_{2}\right)$ as a valid equilibrium requires two more steps: (1) determining parameter conditions which ensure interior solutions, $\hat{x}_{1}, \hat{y}_{1}, \widehat{K}_{2}>0$; and (2) verifying that both players indeed find it optimal to fully use their installed capacity in Stage 2, with $\hat{x}_{1}+\hat{y}_{1}=\widehat{K}_{1}$ and $\hat{y}_{2}=\widehat{K}_{2}$.

Step 1. In market $A$, for player $1, \hat{x}_{1}=x_{m}>0$ holds if and only if $x_{f}<\left(a-r_{1}-c_{1}^{A}\right) / b$, which is part (i) of the parameter conditions. In market $B$, for player 1, (9) shows that $\hat{y}_{1}>0$ if and only if $\beta y_{f}<\frac{\left[(2-\sigma) \phi_{1}-\phi_{2}\right]}{(1-\sigma)}$ while, for player 2, (9) implies that $\widehat{K}_{2}>0$ if and only if $\beta y_{f}<\left(2 \phi_{2}-\phi_{1}\right)$; taken together, this gives part (ii) of the parameter conditions. (Note that part (ii) implies $\beta y_{f}<\min \left\{\phi_{1}, \phi_{2}\right\}$, which will be useful in later proofs.)

Step 2. In Stage 2, player 1 will find it optimal to fully use all of its installed capacity, such that $\hat{x}_{1}+\hat{y}_{1}=\widehat{K}_{1}$, as long as its marginal revenue at $\left(\widehat{\mathbf{K}}, \hat{x}_{1}, \hat{y}_{1}, \hat{y}_{2}\right)$ exceeds its production cost in each market. This holds since (1) implies that $\left(M R_{1}^{A}-c_{1}^{A}\right)=\left(M R_{1}^{B}-c_{1}^{B}\right)=r_{1}>0$. For player 2, similarly, if $M R_{2}^{B}>c_{2}^{B}$ at $\left(\widehat{\mathbf{K}}, \hat{x}_{1}, \hat{y}_{1}, \hat{y}_{2}\right)$ then $\hat{y}_{2}=\widehat{K}_{2}$ is optimal. Recalling $M R_{2}^{B}\left(\hat{y}_{1}, \widehat{K}_{2} ; y_{f}\right)=\left[\alpha-\beta\left(\hat{y}_{1}+y_{f}\right)-\right.$ $\left.2 \beta \widehat{K}_{2}\right]$ and using $\hat{y}_{1}, \widehat{K}_{2}$ from (9) gives that $M R_{2}^{B}\left(\hat{y}_{1}, \widehat{K}_{2} ; y_{f}\right)>c_{2}^{B}$ if and only if:

$$
\left(\alpha-c_{2}\right)>\beta\left(\hat{y}_{1}+y_{f}\right)+2 \beta \widehat{K}_{2}=\frac{\left(3 \phi_{2}-\sigma \phi_{1}\right)-\sigma \beta y_{f}}{(3-2 \sigma)} .
$$

This condition is easier to satisfy for higher values of $y_{f}$; noting that $\left(\alpha-c_{2}\right) \equiv\left(\phi_{2}+r_{2}\right)$ it follows that a sufficient condition, that applies for all $y_{f} \geq 0$, is:

$$
\left(\phi_{2}+r_{2}\right)>\frac{\left(3 \phi_{2}-\sigma \phi_{1}\right)}{(3-2 \sigma)} \Leftrightarrow r_{2}>\frac{\sigma}{(3-2 \sigma)}\left(2 \phi_{2}-\phi_{1}\right)
$$

which is the third part of the parameter conditions, thus completing the proof.

Proof of Proposition 1. For part (a), using $\left(\hat{y}_{1}, \hat{y}_{2}\right)$ from Lemma 2 gives an expression for player 2's market share:

$$
\hat{s}_{2}(\sigma) \equiv \frac{\hat{y}_{2}}{\hat{y}_{1}+\hat{y}_{2}+y_{f}}=\frac{\left(2 \phi_{2}-\phi_{1}\right)-\beta y_{f}}{\left[(1-\sigma) \phi_{1}+\phi_{2}\right]+(1-\sigma) \beta y_{f}} \in(0,1),
$$


where $\hat{s}_{2}(\sigma) \in(0,1)$ follows from part (ii) of the parameter condition from Lemma 2 . It is easy to see that $\hat{s}_{2}^{\prime}(\sigma)>0$ and, as $y_{f}$ remains unchanged, it follows that $\hat{s}_{1}^{\prime}(\sigma)<0$, as claimed.

Player 2's equilibrium profits $\widehat{\Pi}_{2}^{B}=\left[R_{2}^{B}\left(\hat{y}_{1}, \hat{y}_{2}\right)-\left(r_{2}+c_{2}^{B}\right) \hat{y}_{2}\right]$ in market $B$ can be written as:

$$
\widehat{\Pi}_{2}^{B}(\sigma)=\beta(1-\sigma)\left(\hat{y}_{2}\right)^{2}=\frac{1}{\beta} \frac{(1-\sigma)}{(3-2 \sigma)^{2}}\left[\left(2 \phi_{2}-\phi_{1}\right)-\beta y_{f}\right]^{2},
$$

since $M R_{2}^{B}+\beta \sigma y_{2}=\hat{p}^{B}-\beta(1-\sigma) \hat{y}_{2}=r_{2}+c_{2}^{B}$ by (5), and using $\hat{y}_{2}$ from Lemma 2. Differentiation shows that:

$$
\frac{\partial \widehat{\Pi}_{2}^{B}(\sigma)}{\partial \sigma}=\frac{1}{\beta} \frac{(1-2 \sigma)}{(3-2 \sigma)^{3}}\left[\left(2 \phi_{2}-\phi_{1}\right)-\beta y_{f}\right]^{2}>0
$$

which is positive since $\sigma \in\left(0, \frac{1}{2}\right)$. Similarly, player 1's profits $\hat{\Pi}_{1}^{B}=\left[R_{1}^{B}\left(\hat{y}_{1}, \hat{y}_{2}\right)-\left(r_{1}+c_{1}^{B}\right) \hat{y}_{1}\right]$ from market $B$ can be written as:

$$
\widehat{\Pi}_{1}^{B}(\sigma)=\beta\left(\hat{y}_{1}\right)^{2}=\frac{1}{\beta} \frac{\left\{\left[(2-\sigma) \phi_{1}-\phi_{2}\right]-(1-\sigma) \beta y_{f}\right\}^{2}}{(3-2 \sigma)^{2}},
$$

since $M R_{1}^{B}=\hat{p}^{B}-\beta \hat{y}_{1}=r_{1}+c_{1}^{B}$ by (3), and using $\hat{y}_{1}$ from Lemma 2. Differentiation shows that:

$$
\frac{\partial \widehat{\Pi}_{1}^{B}(\sigma)}{\partial \sigma}=-\frac{1}{\beta} \frac{2\left[\left(2 \phi_{2}-\phi_{1}\right)-\beta y_{f}\right]}{(3-2 \sigma)^{3}}\left\{\left[(2-\sigma) \phi_{1}-\phi_{2}\right]-(1-\sigma) \beta y_{f}\right\}<0,
$$

which is negative given part (ii) of the parameter condition from Lemma 2. For part (b), using Lemma 1, players' joint outputs and prices in market $B$ satisfy:

$$
\hat{y}_{1}+\hat{y}_{2}+y_{f}=\frac{\left[(1-\sigma) \phi_{1}+\phi_{2}+(1-\sigma) \beta y_{f}\right]}{\beta(3-2 \sigma)}
$$

and so player $j$ 's price in market $B$ is given by:

$$
\hat{p}_{j}^{B}(\sigma)=\alpha_{j}-\frac{\left[(1-\sigma) \phi_{1}+\phi_{2}+(1-\sigma) \beta y_{f}\right]}{(3-2 \sigma)} .
$$

Differentiation yields $\frac{\partial}{\partial \sigma} \hat{p}_{j}^{B}(\sigma)=-\frac{\left[\left(2 \phi_{2}-\phi_{1}\right)-\beta y_{f}\right]}{(3-2 \sigma)^{2}}<0$, confirming that market prices decline and thus completing the proof.

Proof of Proposition 2. Differentiation of the equilibrium Herfindahl index gives $\widehat{H}^{\prime}(\sigma)=2\left[\hat{s}_{1}(\sigma) \hat{s}_{1}^{\prime}(\sigma)+\hat{s}_{2}(\sigma) \hat{s}_{2}^{\prime}(\sigma)\right]$. Combining Proposition 1(a) and Proposition 1(b), it follows that $\hat{s}_{2}^{\prime}(\sigma)+\hat{s}_{1}^{\prime}(\sigma)>0>\hat{s}_{1}^{\prime}(\sigma)$; the market share of the competitive fringe declines with $\sigma$, given that total market sales $\hat{y}_{1}+\hat{y}_{2}+y_{f}$ rise with $\sigma$ and $y_{f}$ remains unchanged. By assumption, player 2 has a higher profitability index, $\phi_{2} \geq \phi_{1}$, and so $\hat{s}_{2}(\sigma) \geq \hat{s}_{1}(\sigma)$ using Lemma 2. Taken together, this implies that $\widehat{H}^{\prime}(\sigma)>0$ while $\partial \hat{p}_{j}^{B} / \partial \sigma<0$ (for $j=1,2$ ) by Proposition 1(b).

Proof of Proposition 3. For part (a), holding players' capacity investments fixed, totally differentiating (1) shows that: 


$$
\left.\frac{\partial \hat{y}_{1}}{\partial y_{f}}\right|_{\hat{K}_{1} \text { fixed }}=\frac{\frac{\partial M R_{1}^{A}}{\partial y_{f}}-\frac{\partial M R_{1}^{B}}{\partial y_{f}}}{-\left(\frac{\partial M R_{1}^{A}}{\partial y_{1}}-\frac{\partial M R_{1}^{B}}{\partial y_{1}}\right)}=\frac{\frac{\partial M R_{1}^{A}}{\partial K_{2}}-\frac{\partial M R_{1}^{B}}{\partial K_{2}}}{-\left(\frac{\partial M R_{1}^{A}}{\partial y_{1}}-\frac{\partial M R_{1}^{B}}{\partial y_{1}}\right)}=\frac{\partial y_{1}}{\partial K_{2}}=-\sigma,
$$

where the strategic effect $\sigma=\frac{1}{2}[\beta /(\beta+b)] \in\left(0, \frac{1}{2}\right)$ by Lemma 1 . Since $\widehat{K}_{1}$ is fixed and $\hat{x}_{1}+\hat{y}_{1}=\widehat{K}_{1}$ by assumption, it follows immediately that $\left.\frac{\partial \hat{x}_{1}}{\partial y_{f}}\right|_{\hat{K}_{1} \text { fixed }}+\left.\frac{\partial \hat{y}_{1}}{\partial y_{f}}\right|_{\hat{K}_{1} \text { fixed }}=0$. For part (b), the expressions for $\left.\frac{\partial \hat{x}_{1}}{\partial y_{f}}\right|_{\hat{K}_{1} \text { optimal }},\left.\frac{\partial \hat{y}_{1}}{\partial y_{f}}\right|_{\hat{K}_{1} \text { optimal }}$, and $\left.\frac{\partial \hat{y}_{2}}{\partial y_{f}}\right|_{\hat{K}_{2} \text { optimal }} \quad \begin{aligned} & \left.\left.\partial y_{f}\right|_{\hat{K}_{1} \text { fixed }} \partial y_{f}\right|_{\hat{K}_{1} \text { fixed }} \\ & \text { follow immediately by differentiating the expressions }\end{aligned}$ for $\hat{x}_{1}, \hat{y}_{1}$, and $\hat{y}_{2}$ from Lemma 2 . 